\title{
FESTINES Y PODER EN CHAVÍN DE HUÁNTAR DURANTE EL PERÍODO FORMATIVO TARDÍO EN LOS ANDES CENTRALES
}

\author{
FEASTING AND POWER DURING THE LATE FORMATIVE \\ PERIOD AT CHAVÍN DE HUÁNTAR
}

Christian Mesía Montenegro ${ }^{1}$

\begin{abstract}
Los festines han sido comprendidos como el centro de diferentes tipos de interacción entre varios segmentos de una esfera social, auspiciados al nivel supracomunal pueden brindar información sobre las relaciones entre aquellos quienes lo ofrecieron y aquellos quienes eran invitados a los mismos. En este artículo se presenta evidencia de festines supracomunales, la cual fue recuperada de un extenso basural estratificado, excavado en Chavín de Huántar, el cual se ubica cronológicamente en el Formativo Tardío de los Andes Centrales (800-500 a.C.). En primera instancia se analizan las características formales de los depósitos que componen el basural, para luego examinarse la diversidad en la incidencia y variabilidad de formas cerámicas, restos de fauna animal, parafernalia narcótica y objetos calificados como exóticos. Finalmente se discuten las implicancias de festines supracomunales en el contexto ceremonial andino, así como las estrategias en el ejercicio de poder llevadas a cabo durante el Formativo Tardío en los Andes Centrales.

Palabras claves: festines, poder, autoridad, Formativo, Chavín de Huántar, Perú.
\end{abstract}

Feasts have been understood as the locus of different types of interactions between various segments of the social sphere. Sponsored feasts at the supra-household level can provide information regarding the relationship between those who hosted the feasts and those who attended them. This paper presents evidence for supra-household feasts, retrieved from a large, stratified midden excavated at the site of Chavín de Huántar that dates to the Late Formative period (800-500 BC) in the Central Andes. I first analyze the formal characteristics of the midden deposits, and then examine variation in vessel types and frequencies, faunal remains, narcotic paraphernalia, and exotic items. Finally, I discuss the implications of supra-household feasts in the context of Andean ceremonialism and power strategies during the Central Andes Late Formative period.

Key words: Feasts, power, authority, Formative, Chavín de Huántar, Peru.

Durante el período Formativo de los Andes Centrales (1.800-200 a.C.) se dio una gran profusión de centros ceremoniales en la costa y sierra norte, y la costa y sierra central, en donde los sistemas religiosos regularon, entre varios otros aspectos, los usos y costumbres del poblador de estas regiones. En algunos casos estos centros cumplieron el rol de satisfacer las necesidades religiosas de una población, a cambio de la fuerza de trabajo necesaria para que el sistema religioso representado en el centro pueda supervivir y prevalecer entre otros (Clark y Blake 1996; Hayden 1995; Renfrew y Cherry 1986). Los centros ceremoniales fueron generadores y receptores de una intensa vida social, la cual regulaba diversos aspectos de la naturaleza humana, como aquellos aspectos ligados a la satisfacción espiritual o al adecuado funcionamiento del sistema social (Aldenderfer 2012; Burger 1992; Durkheim 1912). Desde un punto de vista más escéptico, esta necesidad básica de cohesión social, pudo ser el objeto de una consiente y planificada manipulación por parte de aquellos segmentos de la sociedad quienes gozaban de privilegiadas posiciones de poder y autoridad (Rick 2005, 2008).

Siguiendo esta última línea de pensamiento, este artículo describe y articula la evidencia recuperada de un extenso basural, excavado en el sector Wacheqsa de Chavín de Huántar, el cual argumento, fue originado debido a la deposición de desechos producidos por el consumo colectivo de alimentos y bebidas, en otras palabras, festines supracomunales, los que fueron materializaciones

\footnotetext{
1 Universidad San Ignacio de Loyola. Escuela de Postgrado. Av. La Fontana 750. La Molina, Lima, Perú. cmesia@usil.edu.pe
} 
del poder ejercido por las autoridades del centro ceremonial. El concepto de supracomunal excede a lo comunal (conjunto de unidades domésticas bajo una circunscripción territorial) y a lo doméstico (unidad doméstica).

Los festines, cuando suceden al nivel supracomunal, presentan diferentes niveles, ya sea políticos, sociales e incluso espaciales, en donde el ejercicio de poder y autoridad sirve para reforzar roles y funciones al interior del sistema social (Dietler 1995; Dietler y Herbich 2001; Phillips y Sebastian 2004).

\section{El Sitio}

El centro ceremonial de Chavín de Huántar está ubicado en la provincia de Huari, departamento de Ancash, en la sierra norcentral del Perú (Figura 1) a $3.180 \mathrm{msm}$, en la intersección de los ríos Wacheqsa y Mosna (Figura 2). La mención Chavín de Huántar ha sido bastante ubicua en discusiones referentes a la complejidad social temprana de los Andes Centrales, debido a su compleja escultura en piedra, arquitectura monumental, plataformas superpuestas, galerías, y plazas abiertas, las cuales han convertido a este lugar en uno de los sitios en función más impresionantes del Formativo Medio ${ }^{1}$ (1.200-800 a.C.) y Tardío (800-500 a.C.) de los Andes Centrales. Como resultado de su impresionante arquitectura, gran parte del trabajo arqueológico desarrollado en Chavín de Huántar se ha centrado en el área monumental (Bennett 1944; Kauffman-Doing y González 1993; Kembel 2001, 2008; Lumbreras 1977, 1989, 1993, 2007; Lumbreras y Amat 1965, 1969; Rick 2008; Rick et al. 1998; Rowe 1962; Tello 1960), con la intención de comprender la secuencia arquitectónica del sitio, el significado de la iconografía expuesta en las esculturas que adornaron la fachada del mismo, así como la construcción de secuencias cronológicas absolutas y relativas. Sin embargo, es pertinente mencionar que hubo esfuerzos centrados en conocer la arqueología del entorno inmediato del núcleo monumental de Chavín de Huántar, como los trabajos y referencias de Rivero² (1851), Espejo (1956), Diessl (2004), Burger (1982, 1984, 1998), Contreras (2007, 2009), Mesia (2007) y Sayre (2010).

En Chavín de Huántar he investigado el sector Wacheqsa, ubicado inmediatamente al norte del núcleo monumental, enclaustrado por los ríos Wacheqsa, Mosna y la plataforma norte del ya mencionado núcleo monumental (Figura 3). Tello lo describe como un "campo trapezoidal, de $60 \mathrm{~m}$ de largo y $50 \mathrm{~m}$ de ancho, mirando hacia el río Wacheqsa y a 3 m del montículo D" (Tello 1960:317). Espacialmente, este sector se emplaza entre el núcleo monumental y el asentamiento doméstico, que se extendió hacia el norte, en el terreno en el cual se ubica el pueblo moderno de Chavín de Huántar, tal cual lo reporta Rivero en

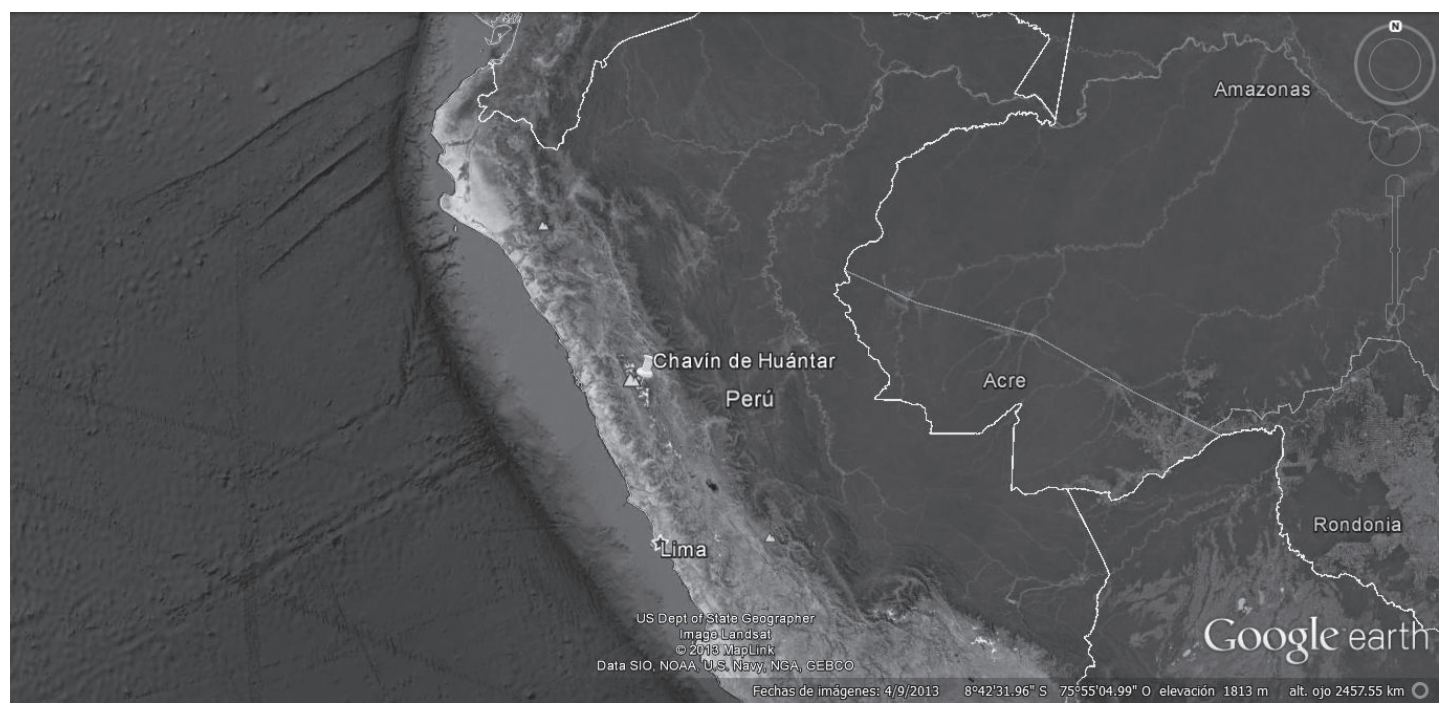

Figura 1. Mapa del Perú con la ubicación de Chavín de Huántar. Map of Peru showing the location of Chavín de Huántar. 


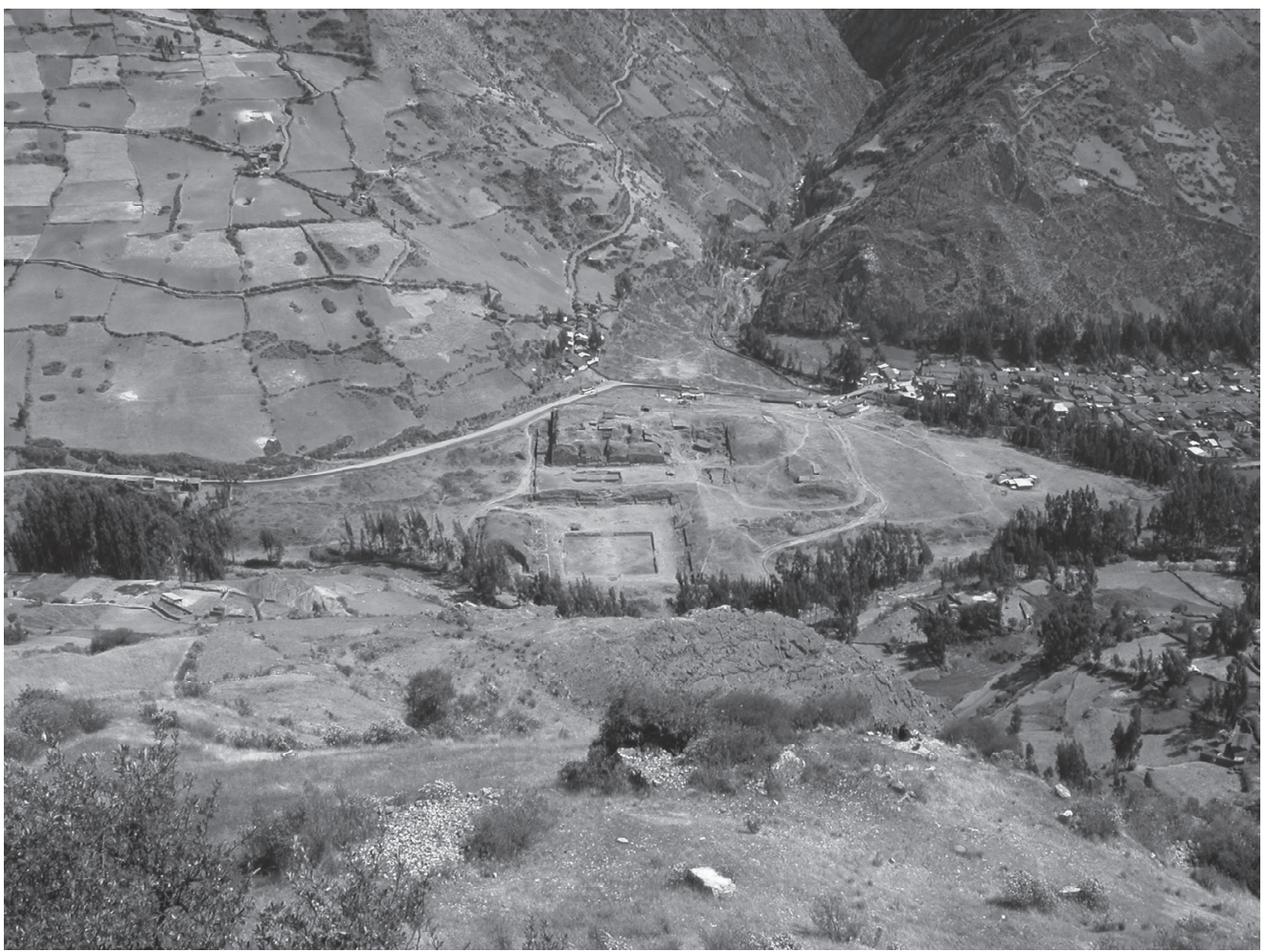

Figura 2. Vista de Chavín de Huántar desde la cima de la ribera este del río Mosna. Foto tomada por John Wolf. View of Chavín de Huántar from the east side of the Mosna River. Photo taken by John Wolf.

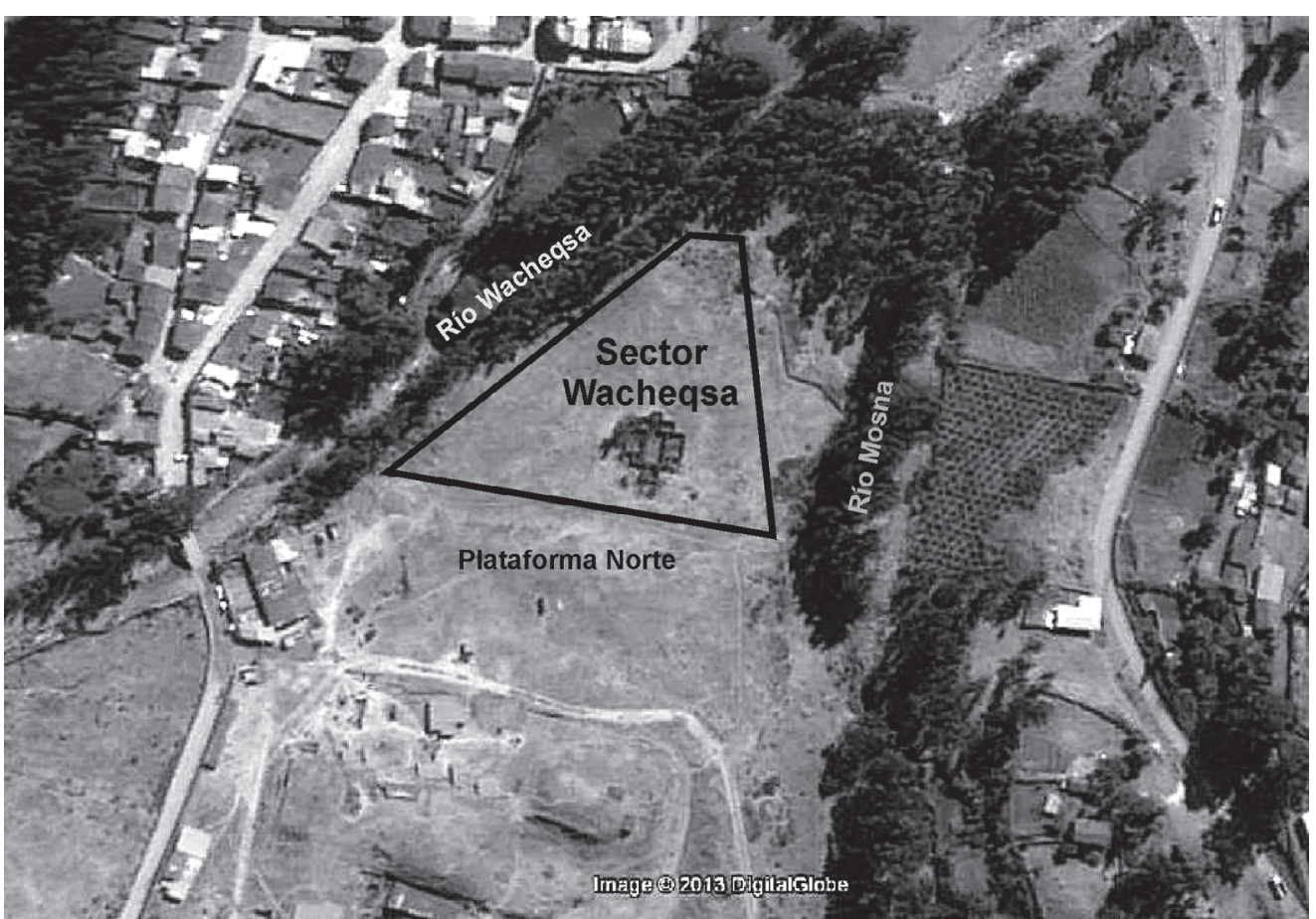

Figura 3. Mapa del sector Wacheqsa.

Map of the Wacheqsa sector. 
1851 quien indica que "la mayor parte de las casas de Chavín y sus alrededores están construidas sobre acueductos" (Rivero 1851:285), información que es corroborada y ampliada posteriormente por Burger (1978, 1984, 1998).

El sector Wacheqsa cubre un área de 1,4 ha, con una pendiente pronunciada de $15,85^{\circ}$ hacia el norte. La topografía actual de este sector es el resultado del aluvión que cayó sobre el centro ceremonial el 17 de enero de 1945, proveniente del río Wacheqsa, fenómeno que cambió sustancialmente la topografía del área. En sus notas de campo no publicadas, Tello indica que hubo al menos tres plataformas en 1940, cubiertas por pequeños campos agrícolas en donde se cultivaba maíz "pasando por el norte del edificio [se debe haber referido al edificio $\mathrm{C}$ o D] hay un terreno dividido entre dos o tres plataformas, las cuales eran utilizadas como tierras de cultivo" (Tello 1940:25) (Figura 4). Este espacio era parte del centro ceremonial, pero no tenía ningún tipo de arquitectura monumental en superficie.

\section{La Prehistoria del Sector Wacheqsa}

El sector Wacheqsa estuvo ocupado entre 1200 y 500 a.C. (Mesía 2007; Rick et al. 2009) (Tablas 1 y 2) (Figura 5) durante el Formativo Medio y Tardío.

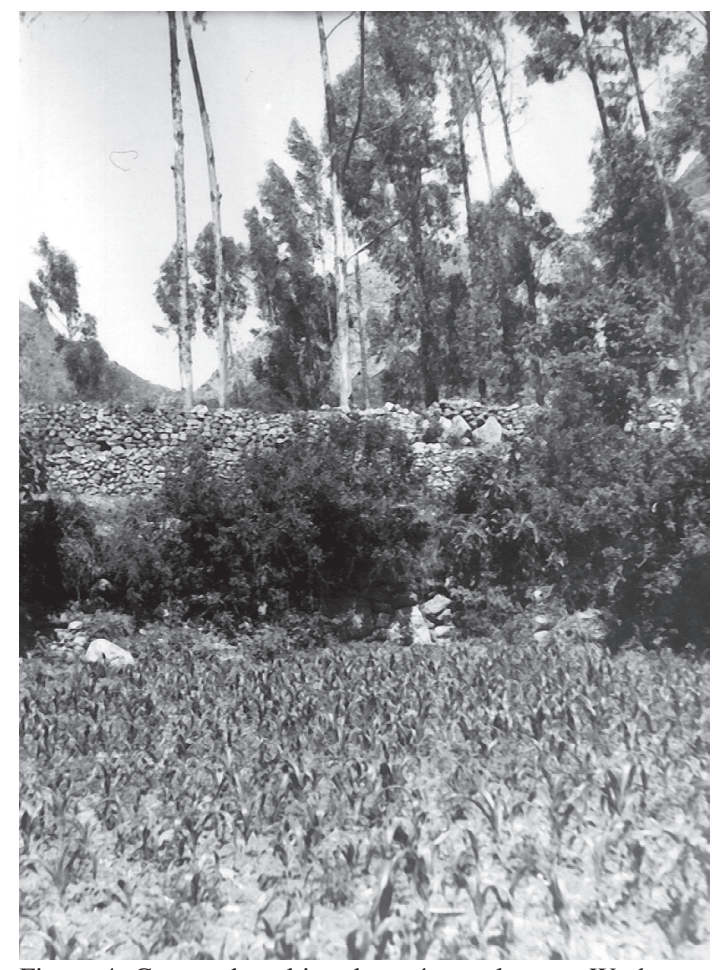

Figura 4. Campo de cultivo de maíz en el sector Wacheqsa, ca. 1940. Archivo Tello del Museo Nacional de Arqueología, Antropología e Historia del Perú.

Agricultural field planted in maize in the Wacheqsa sector, ca. 1940. Tello Archive, Museo Nacional de Arqueología, Antropología e Historia del Perú.

Tabla 1. Cuadro cronológico del sector Wacheqsa.

Chronological chart for the Wacheqsa sector.

\begin{tabular}{clll}
\hline Fechas & \multicolumn{1}{c}{ Fase } & \multicolumn{1}{c}{ Unidades espaciales } & Cerámica \\
\hline & Moderna & Tierra agrícola, canal moderno, aluvión & \\
800-500 a.C. & Formativo Tardío & Basural, cuartos de piedra, plataformas tardías & Janabarroide \\
1200-800 a.C. & Formativo Medio & Plataformas tempranas, Correntera de agua & Urabarroide \\
\hline
\end{tabular}

Tabla 2. Fechados radiocarbónicos en orden estratigráfico. Radiocarbon dates in stratigraphic order.

\begin{tabular}{ccccccccl}
\hline & Muestra \# & Código Harris Matrix & $\delta 13 \mathrm{C}$ & $\mathrm{F}$ & \pm error & 14C edad a.p. & \pm error & Unidad espacial \\
\hline 1 & AA75390 & 210 & $-22,4$ & 0,7325 & 0,0032 & 2500 & 35 & Cuartos de piedra \\
2 & AA75388 & 440 & $-22,6$ & 0,711 & 0,0033 & 2740 & 37 & Plataformas tardías \\
3 & AA75389 & 135 & $-21,8$ & 0,7259 & 0,0031 & 2573 & 34 & Basural \\
4 & AA75382 & 144 & $-22,5$ & 0,7342 & 0,0032 & 2481 & 35 & Basural \\
5 & AA75384 & 154 & $-22,6$ & 0,7315 & 0,0032 & 2512 & 35 & Basural \\
6 & AA75385 & 607 & $-23,4$ & 0,7084 & 0,0031 & 2769 & 35 & Plataformas tempranas \\
7 & AA75387 & 516 & $-22,2$ & 0,725 & 0,0033 & 2580 & 36 & Plataformas tempranas \\
8 & AA75383 & 314 & $-23,7$ & 0,7164 & 0,0031 & 2679 & 35 & Correntera de agua \\
9 & AA75386 & 614 & $-21,8$ & 0,7177 & 0,0031 & 2664 & 35 & Plataformas tempranas \\
10 & GX31647 & 524 & & & & 2880 & 40 & Plataformas tempranas \\
\hline
\end{tabular}


OxCal v4.2.2 Bronk Ramsey y Lee (2013) r5 Atmospheric data from Reimer et al. (2009):

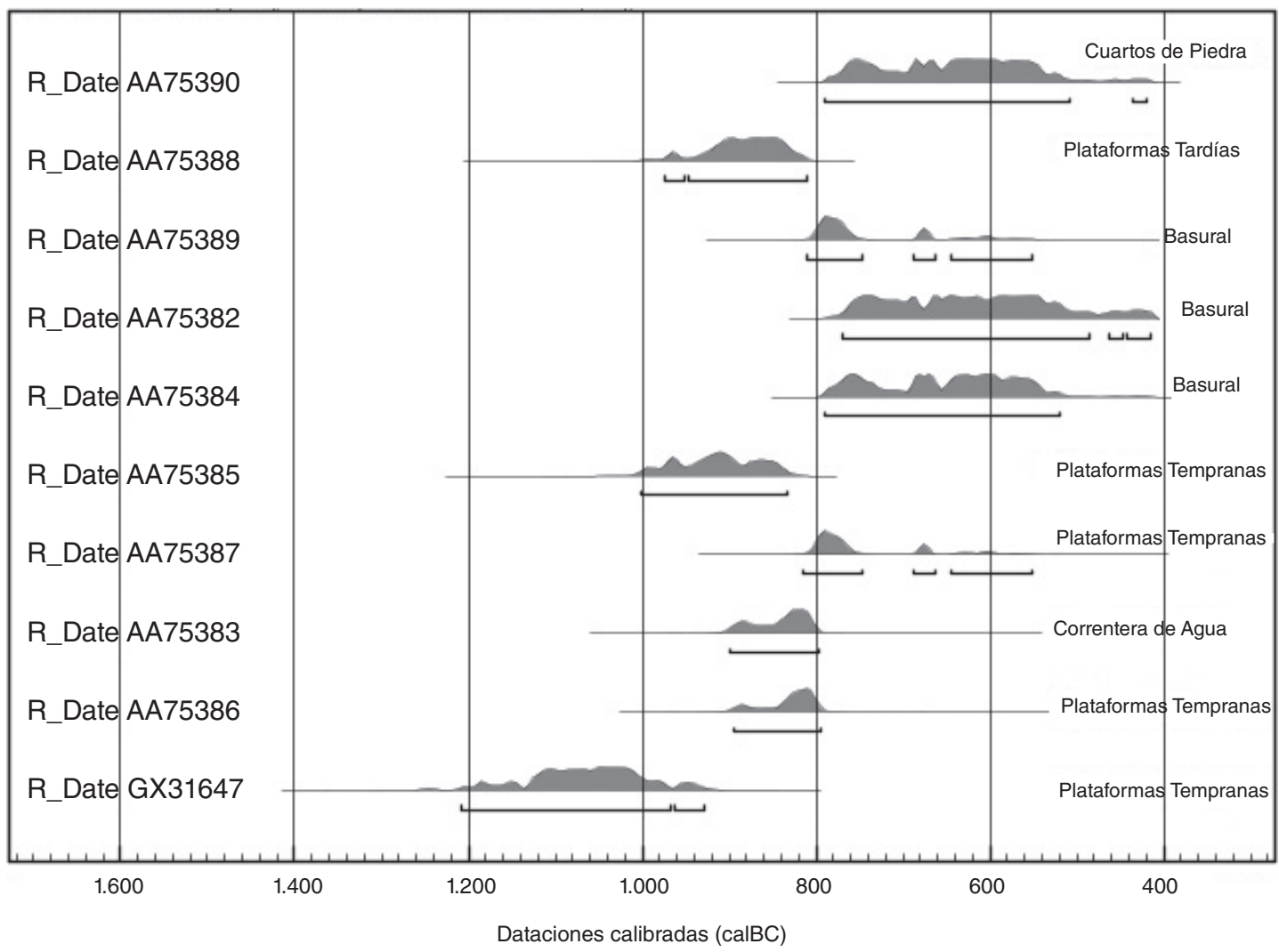

Figura 5. Fechados radiocarbónicos del sector Wacheqsa en orden estratigráfico.

Radiocarbon dates from the Wacheqsa sector in stratigraphic order.

He dividido la ocupación prehistórica de este sector en dos fases:

La más antigua (1.200-800 a.C.) (Figura 6) comprende dos unidades espaciales, la de Plataformas Tempranas y Correntera de Agua. La unidad de Plataformas Tempranas representa al asentamiento doméstico más antiguo presente en este sector mientras que la de Correntera de Agua provee evidencia de la canalización del río Wacheqsa durante el Formativo Medio.

La ocupación más tardía (800-500 a.C.) (Figura 7) presenta tres unidades espaciales, la de Plataformas Tardías, Cuartos de Piedra y Basural. La unidad de Cuartos de Piedra incorpora la presencia de artesanos en el Sector Wacheqsa, el Basural proporciona evidencia de la ocurrencia de festines supracomunales en Chavín de Huántar, mientras que la unidad espacial de Plataformas Tardías parece ser un área intermedia entre estas dos unidades.

\section{El Basural}

Esta unidad espacial se ubica al extremo sur del sector Wacheqsa, sobre la unidad de Correntera de Agua y ha sido identificada en las unidades WQ7SIIIU4, SIIIU4A, SIVU4 y SIVU4. Comprende un área y volumen total estimado de $48 \mathrm{~m}^{2}$ y 83 $\mathrm{m}^{3}$ respectivamente, con un grosor de cerca de $2 \mathrm{~m}$ como promedio. La superficie de esta unidad espacial se localiza a un metro bajo superficie en promedio, tuvo 44 estratos distribuidos entre las unidades de excavación mencionadas (Figura 8) (Tabla 3). Se caracteriza por presentar un suelo de matriz compacta a semicompacta mezclada con piedras angulares de tamaño mediano y grande, además de cantos rodados y una gran cantidad de materiales arqueológicos.

Tres grandes eventos de deposición fueron identificados en las unidades excavadas. El evento más 


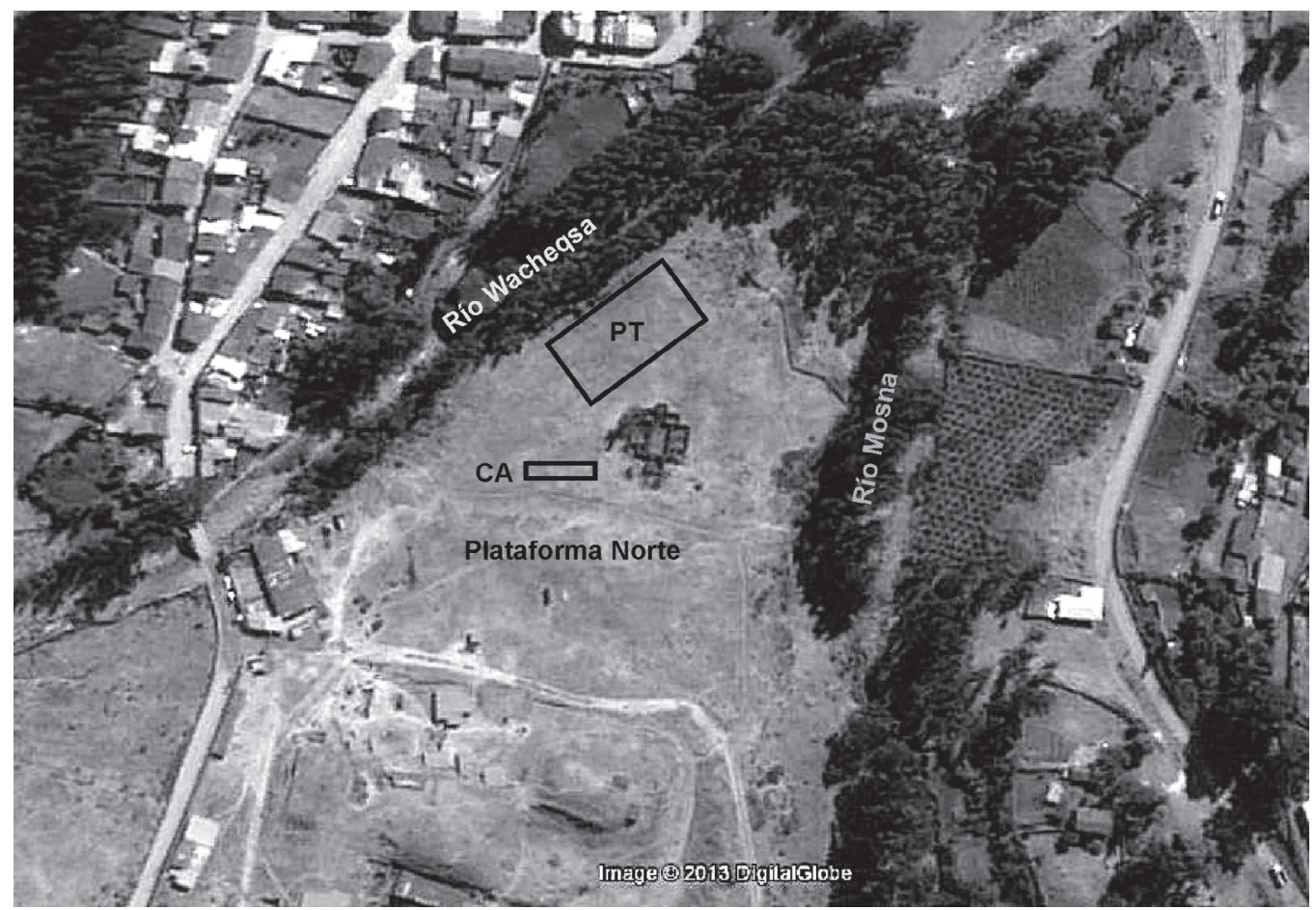

Figura 6. Unidades espaciales del Formativo Medio.

Middle Formative Spatial Units.

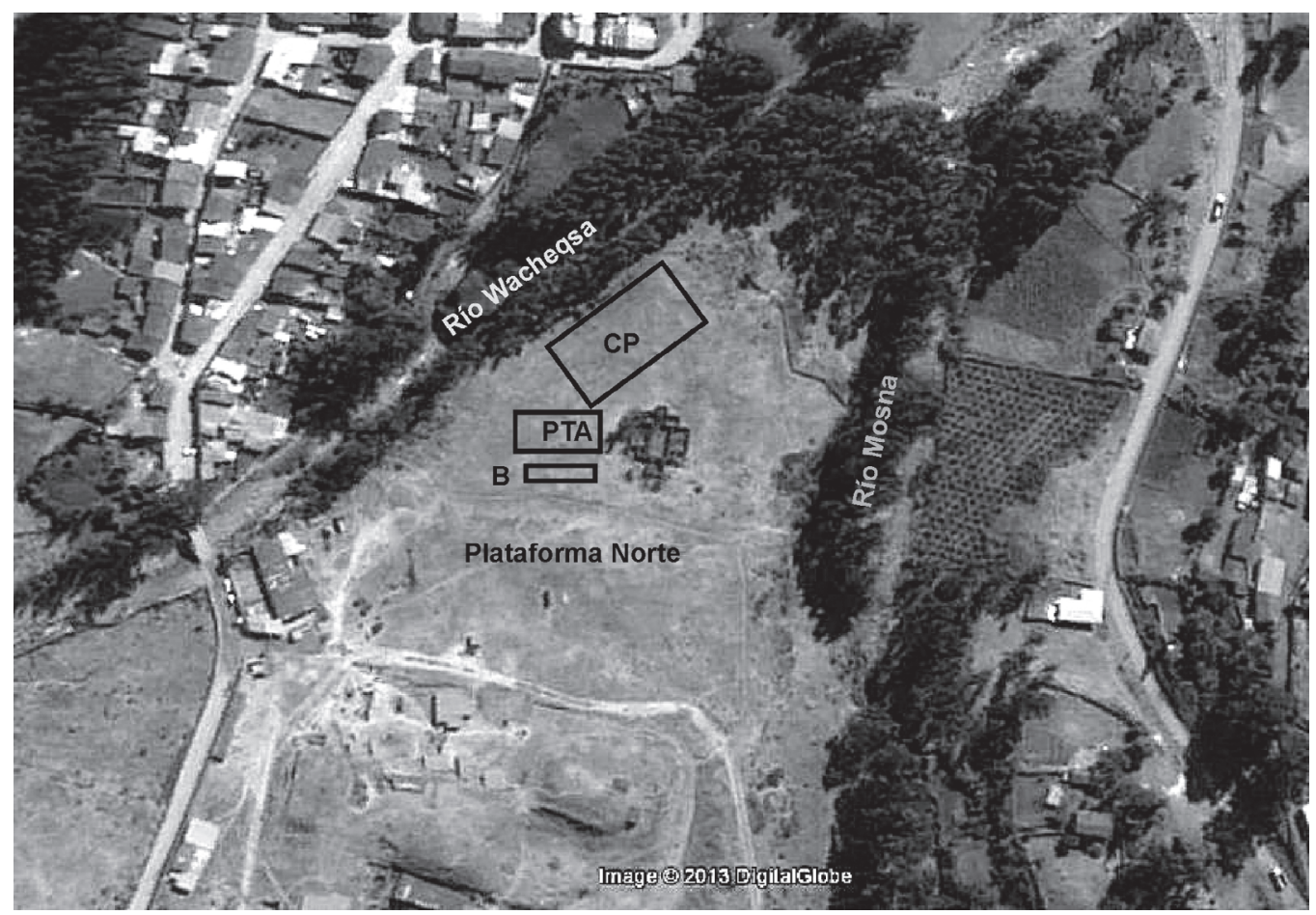

Figura 7. Unidades espaciales del Formativo Tardío.

Late Formative Spatial Units. 
Tabla 3. Estratos excavados y códigos de la Matriz Harris del basural.

Excavated strata and codes used in the Harris Matrix of the midden.

\begin{tabular}{|c|c|c|}
\hline Unidad de Excavación & Estrato & Código de Matriz de Harris \\
\hline WQ7SIV4 & 4 & 112 \\
\hline WQ7SIII4 & 6 & 113 \\
\hline WQ7SIV3 & 6 & 114 \\
\hline WQ7SIV4 & 6 & 115 \\
\hline WQ7SIV4 & $6 a$ & 116 \\
\hline WQ7SIII4A & 7 & 117 \\
\hline WQ7SIV3 & 7 & 118 \\
\hline WQ7SIV4 & 7 & 119 \\
\hline WQ7SIII4 & 4 & 120 \\
\hline WQ7SIII4 & 5 & 121 \\
\hline WQ7SIV3 & 8 & 122 \\
\hline WQ7SIV4 & 5 & 123 \\
\hline WQ7SIII4A & 9 & 124 \\
\hline WQ7SIV3 & 10 & 125 \\
\hline WQ7SIV4 & 8 & 126 \\
\hline WQ7SIII4A & 10 & 127 \\
\hline WQ7SIII4A & $10 \mathrm{a}$ & 128 \\
\hline WQ7SIV3 & 9 & 129 \\
\hline WQ7SIV4 & 9 & 130 \\
\hline WQ7SIV3 & 12 & 131 \\
\hline WQ7SIV4 & 11 & 132 \\
\hline WQ7SIV3 & 11 & 133 \\
\hline WQ7SIII4 & 7 & 134 \\
\hline WQ7SIII4A & 8 & 135 \\
\hline WQ7SIV3 & 14 & 136 \\
\hline WQ7SIII4 & $7 \mathrm{a}$ & 137 \\
\hline WQ7SIII4A & $7 \mathrm{~b}$ & 138 \\
\hline WQ7SIII4 & 9 & 139 \\
\hline WQ7SIII4 & 8 & 140 \\
\hline WQ7SIII4A & 11 & 141 \\
\hline WQ7SIII4A & 12 & 142 \\
\hline WQ7SIV3 & 13 & 143 \\
\hline WQ7SIV4 & 10 & 144 \\
\hline WQ7SIII4 & 10 & 145 \\
\hline WQ7SIV3 & 15 & 146 \\
\hline WQ7SIV4 & 12 & 147 \\
\hline WQ7SIV4 & 13 & 148 \\
\hline WQ7SIV3 & 16 & 149 \\
\hline WQ7SIV3 & 18 & 150 \\
\hline WQ7SIII4A & 14 & 151 \\
\hline WQ7SIII4A & 15 & 152 \\
\hline WQ7SIV3 & 17 & 153 \\
\hline WQ7SIV4 & 14 & 154 \\
\hline WQ7SIII4A & 19 & 155 \\
\hline
\end{tabular}

antiguo está representado por los estratos 152, 153 y 154 , con una gradiente hacia el este este evento ha sido reconocido como Basural I. El segundo evento deposicional ha sido identificado como Basural II, con una gradiente igualmente pronunciada hacia el este, reconocido en los estratos 140, 141, 142,

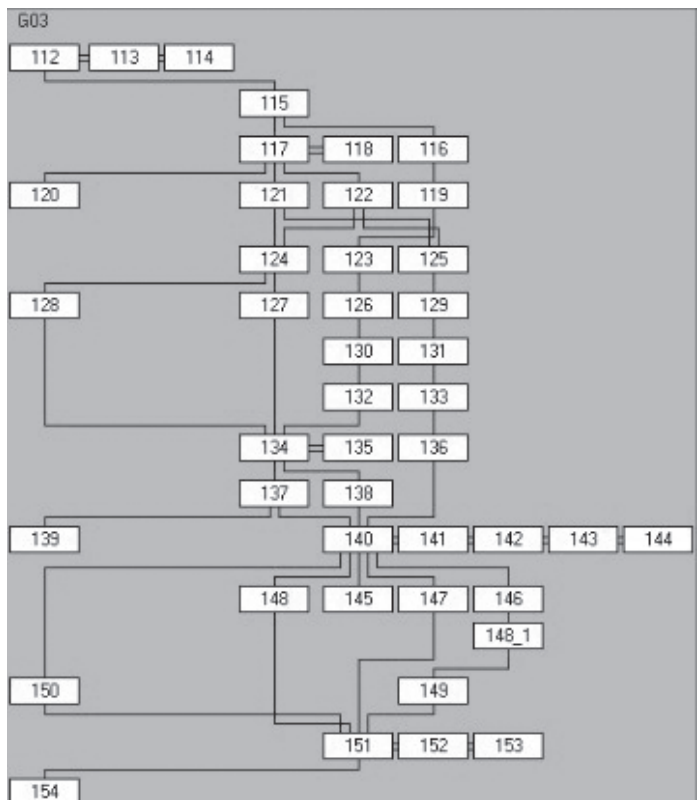

Figura 8. Matriz Harris del Basural.

Harris Matrix of the midden stratigraphy.

143 y 144. El último evento está representado por el Basural III, identificado en los estratos 112, 113 y 114. Del mismo modo que los Basurales I y II, presenta una gradiente hacia el este. Entre Basural I y II existen cinco eventos deposicionales menores, representados por los estratos 146, 147, 148, 149 y 150 . Entre Basural II y III existieron 25 eventos representados por los estratos $115,116,117,118$, $119,120,121,122,123,124,125,126,127,128$, $129,130,131,132,133,134,135,136,137,138$ у 139. Los Basurales I, II y III han sido identificados debido a las similitudes en la naturaleza de los sedimentos entre las cuatro unidades excavadas. Son parte del mismo estrato identificado en distintas unidades de excavación. Entre cada uno de estos grandes eventos deposicionales, otros de menor envergadura fueron identificados. Es necesario indicar que aunque estos eventos son considerados provisionalmente como de menor envergadura, al no haber sido ubicado en más de una unidad, cabe la posibilidad de que algunos de ellos sean parte de eventos deposicionales mayores que aún no han sido localizados (Figuras 9-10).

En total se excavaron $22,03 \mathrm{~m}^{3}$, recuperándose 16.145 fragmentos de material arqueológico, los cuales estuvieron presentes con una densidad de 718,18 fragmentos por metro cúbico excavado (Tabla 4). 


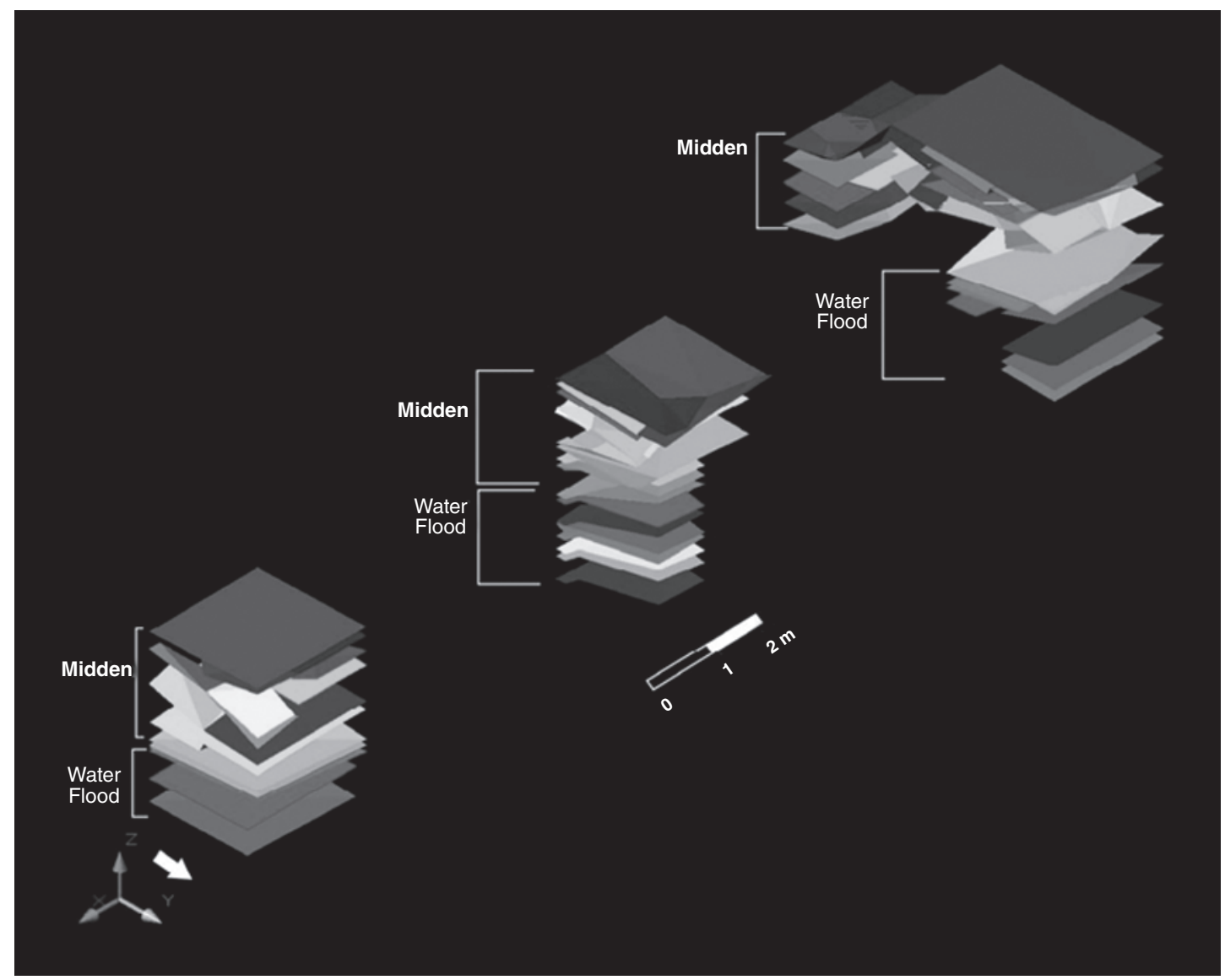

Figura 9. Modelo CAD de la estratigrafía de las unidades espaciales Basural y Correntera de Agua. Nótese la superposición estratigráfica entre ambas.

$C A D$ model of the midden stratigraphy and water flow. Note the stratigraphic superposition between units.

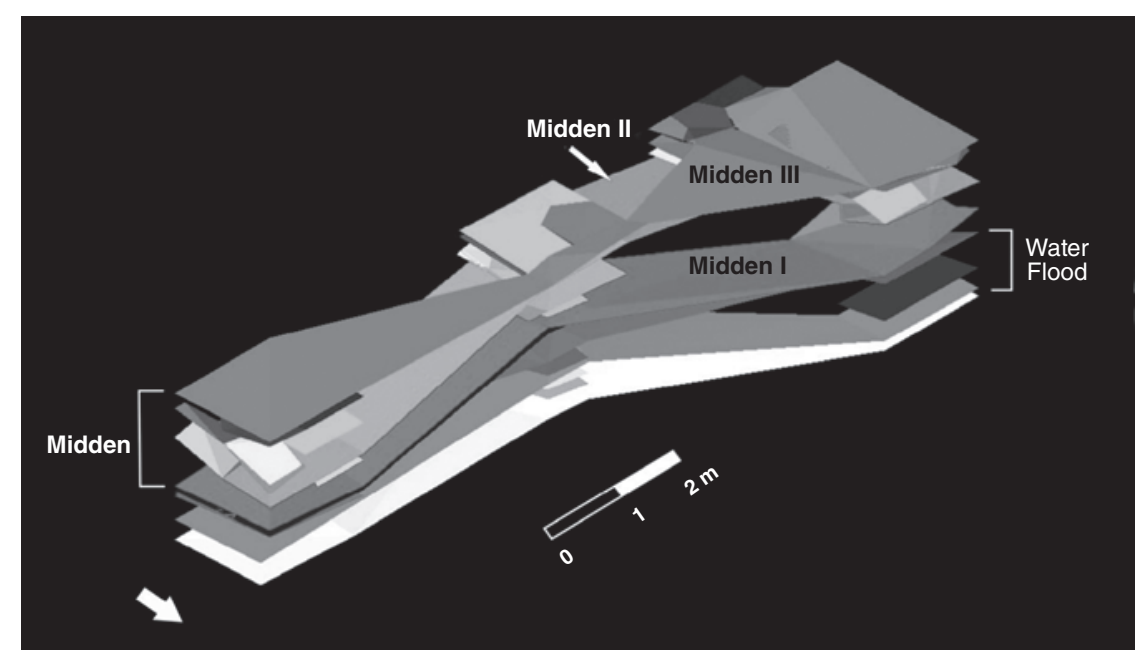

Figura 10. Modelo estratigráfico CAD de las unidades espaciales Basural y Correntera de Agua con extensión de estratos identificados en las excavaciones ejecutadas.

CAD model of the midden stratigraphy and water flow, with the extension of the strata identified into the excavated areas. 


\section{Evidencia Arqueológica de Festines}

La densidad de materiales arqueológicos en el Basural es bastante alta y estadísticamente significativa cuando es comparada con la del resto de unidades espaciales (Figura 11), lo que la separa del resto. El conjunto cerámico recuperado en el Basural es de naturaleza janabarroide ${ }^{3}$ (Rick et al. 2009) (Figura 12).

Los basurales pueden formarse por el agregado de desechos provenientes de distintas áreas de un sitio, de una misma área al interior de un sitio (Boone 1987) o mediante agregados secuenciales de desechos producidos por la misma actividad que se desarrolla cíclicamente en una ubicación específica; los basurales no reflejan una ubicación primaria del material arqueológico, sino una secundaria e incluso hasta terciaria. Si un basural es el agregado de materiales traídos de un mismo lugar, es de esperar encontrar materiales que reflejen esta singularidad, mientras que si el basural es el agregado de desechos proveniente de sitios diversos, es de esperar encontrar materiales que son el resultado de múltiples contextos. Cuando las características físicas de los depósitos de un basural son variadas, es posible argumentar que diferentes comportamientos originaron diversos registros arqueológicos. Por otra parte, si las densidades de materiales así como sus distribuciones son homogéneas, es posible argumentar que un comportamiento similar fue el responsable del registro arqueológico.

En el caso del basural del sector Wacheqsa, los estratos reflejan un comportamiento homogéneo, en términos de composición de suelo y densidad de materiales excavados. En tal sentido, las características físicas de este basural así como la consistente

Tabla 4. Densidades de materiales arqueológicos del basural. Density of archaeological materials recovered from the midden per cubic meter.

\begin{tabular}{|c|c|c|}
\hline Material & Total Recuperado & Densidad \\
\hline Restos de fauna animal & $184,2 \mathrm{~kg}$ & $8,27 \mathrm{~kg} / \mathrm{m}^{3}$ \\
\hline Fragmentos de cerámica llana & $5082,29 \mathrm{~kg}$ & $230,70 \mathrm{~kg} / \mathrm{m}^{3}$ \\
\hline Fragmentos de cerámica decorada & 4417 & 200,49 fragmentos $/ \mathrm{m}^{3}$ \\
\hline Fragmentos de cerámica diagnóstica & 8567 & 388,87 fragmentos $/ \mathrm{m}^{3}$ \\
\hline Fragmentos de pisos y columnas de barro & 2136 & 96,96 fragmentos $/ \mathrm{m}^{3}$ \\
\hline Fragmentos de obsidiana & 554 & 25,15 fragmentos $\mathrm{s} / \mathrm{m}^{3}$ \\
\hline Fragmentos de antracita & 138 & 6,26 fragmentos $/ \mathrm{m}^{3}$ \\
\hline Fragmentos de moluscos & 6 & 0,27 fragmentos $/ \mathrm{m}^{3}$ \\
\hline Puntas de proyectil de cuarcita & 15 & 0,68 fragmentos $/ \mathrm{m}^{3}$ \\
\hline Fragmentos de artefactos de hueso & 62 & 2,81 fragmentos $/ \mathrm{m}^{3}$ \\
\hline Fragmentos de crisocola & 15 & 0,68 fragmentos $/ \mathrm{m}^{3}$ \\
\hline Artefactos líticos & 235 & 10,66 fragmentos $/ \mathrm{m}^{3}$ \\
\hline
\end{tabular}

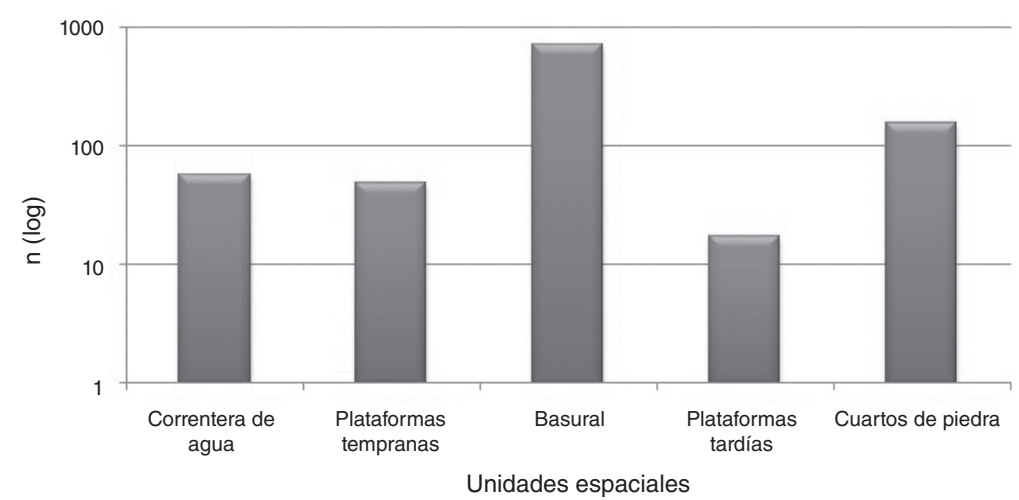

Figura 11. Densidad de materiales arqueológicos por metro cúbico entre todas las unidades espaciales.

Density of archaeological materials per cubic meter per spatial unit. 

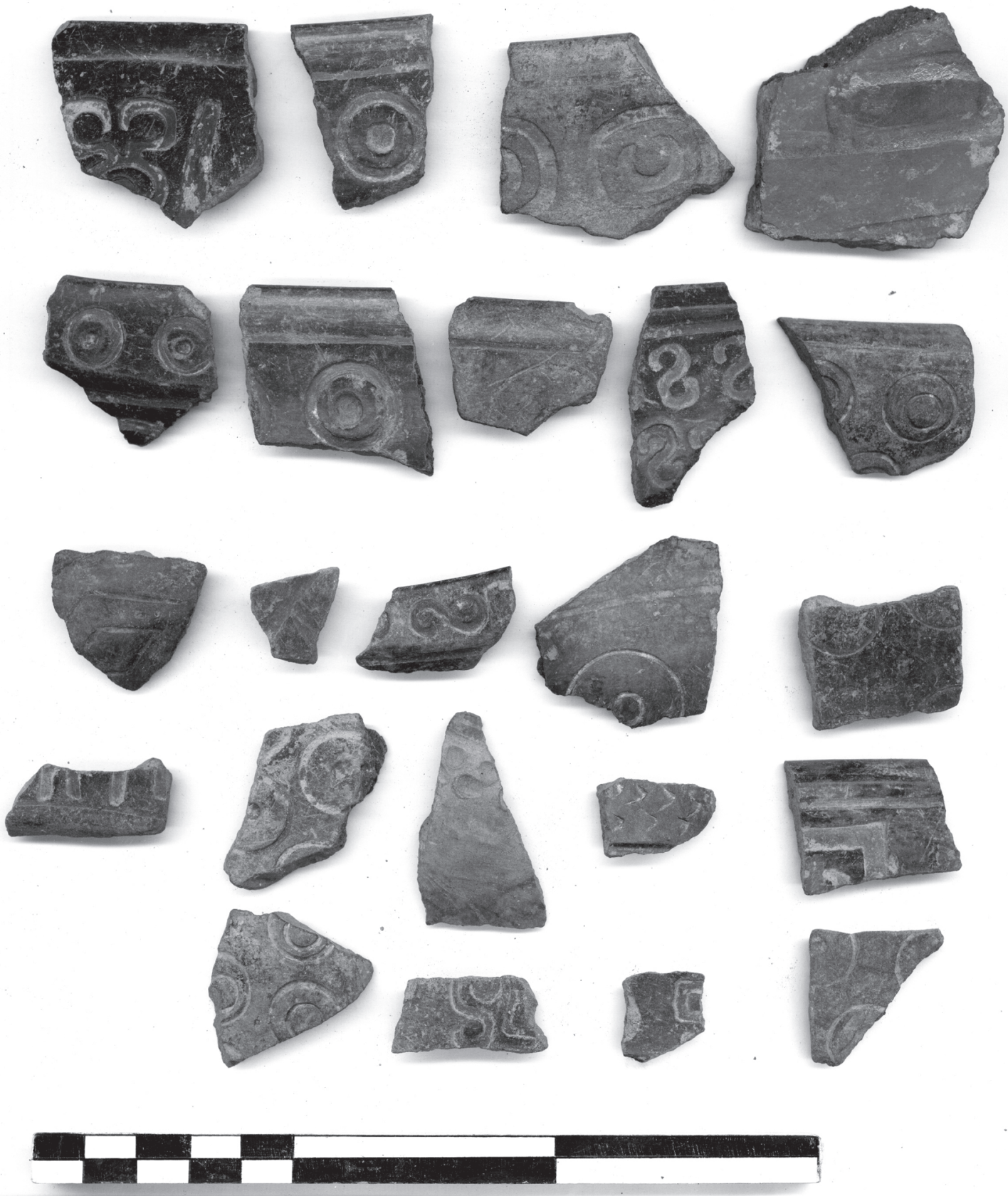

Figura 12. Muestra de la cerámica recuperada en el basural. Sample of ceramics retrieved from the midden.

densidad de materiales arqueológicos en sus estratos, indican que este basural es el producto de una actividad singular, repetida constantemente en el tiempo. Los estratos eran compactos, con abundante suelo entre los materiales. Por consiguiente es importante preguntar ¿qué tipo de actividad fue esta? y ¿de dónde provinieron los materiales presentes en el basural?

Los estratos de este basural se formaron del desecho producido por el consumo colectivo de alimentos y bebidas, en otras palabras, por la ocurrencia de festines supracomunales. Es pertinente 
mencionar que no se han identificado otros contextos relacionados con festines supracomunales en Chavín de Huántar durante el Formativo Medio o Formativo Tardío.

Como lo han indicado Dietler y Hayden, es importante diferenciar el consumo comunal del "consumo diario doméstico y del simple intercambio de alimentos sin consumo comunal [traducción del autor]" (Dietler y Hayden 2001:3). Grandes cantidades de alimentos, grandes e inusuales cantidades de vasijas para cocinar y servir de tamaño grande, ítems exóticos y parafernalia narcótica, en conjunto, son indicadores de festines (Blitz 1993; DeBoer 2001; Dietler y Herbich 2001; Hayden 2001; Mills 1999; Potter 2000; Rosenswig 2007).

A continuación examinaré estos indicadores, de acuerdo con la evidencia material recuperada en el basural del sector Wacheqsa, agregando las siguientes categorías: restos macrobotánicos y restos de muros, paredes, pisos y frisos.

\section{Cerámica}

Un conjunto de 3.020 fragmentos cerámicos diagnósticos fueron analizados de entre las cinco unidades espaciales del sector Wacheqsa. Para este análisis se utilizaron rutinas estadísticas de estimados de densidad kernel (Mesía 2007, 2012). Como resultado de este análisis se identificaron seis tipos de vasijas cerámicas, cuya distribución muestra una consistente variabilidad intrasitio al interior del sector Wacheqsa (Tabla 5) (Mesía 2007, 2012). Entre estos seis tipos, las jarras, ollas sin cuello y cuencos están consistentemente presentes en todas las unidades espaciales prehistóricas, mientras que botellas vasos y platos presentan presencia significativa solamente en el Basural. En esta unidad, la forma más ubicua es el cuenco, con una distribución unimodal en la que los cuencos de tamaño mediano componen más del $50 \%$ de la muestra analizada del Basural. La segunda forma ubicua es la olla sin cuello, la cual representa el $26 \%$ de la muestra analizada del basural, con una distribución bimodal, en la que existe una prevalencia de ollas sin cuello grandes. Tercero en la lista es la jarra, la cual conforma el $11 \%$ de la muestra analizada proveniente del basural, con una distribución unimodal de jarras de tamaño pequeño ${ }^{4}$. El resto de las formas están por debajo del 5\% de la muestra analizada (Figuras 13 y 14). El número elevado de cuencos y especialmente la gran cantidad de cuencos de tamaño mediano indican el consumo de grandes cantidades de comida y el uso de raciones estandarizadas. Los cuencos son vasijas para servir, que pueden ser utilizadas tanto para alimentos sólidos, como para líquidos (DeBoer 2001; Lumbreras 2005). Las ollas sin cuello pueden ser utilizadas para cocinar o para almacenar (Blitz 1993; Lumbreras 2005). Los cuencos poseen bordes no restrictos, lo cual es importante, ya que "los vasijas no restrictas son ventajosas no solamente al momento de retirar los contenidos, sino al momento de colocarlos al interior de la vasija [traducción del autor]" (Rice 1987:241). Adicionalmente las vasijas no restrictas, como los cuencos, muestran los contenidos, lo cual es muy importante en las vasijas para servir.

La distribución bimodal de las ollas sin cuello indica la cocina y/o almacenamiento de diferentes tipos de comidas para pequeñas y grandes cantidades de personas. El tamaño de la olla no refleja solamente la cantidad de comida que es cocinada o almacenada, sino también el tipo de comida que es almacenada o cocinada. El tamaño en las ollas sin cuello puede ser un indicador de la cantidad y tipo de alimento procesado

la relación entre uso y volumen de una vasija, puede ser concebida en términos del tipo de materiales que la vasija contiene, el tamaño, el tiempo en que serán contenidos, el número anticipado de comensales durante ese tiempo y factores microambientales como la disponibilidad de agua y otras necesidades [traducción del autor] (Rice 1987:225).

Las jarras fueron fundamentalmente vasijas para almacenar y servir, fundamentalmente líquidos. Las jarras son vasijas restrictas, con cuellos que impiden que los contenidos se derramen. Están significativamente presentes en el Basural y la jarra de mayor popularidad es la de tamaño mediano. Es interesante mencionar que las botellas tan solo componen el $3 \%$ de la muestra analizada, indicando que las jarras antes que las botellas fueron los contenedores más populares para servir y almacenar líquidos.

Los alimentos probablemente fueron cocinados, almacenados y transportados al lugar en el cual se desarrolló el festín, para luego ser distribuidos en cuencos. No es fuera de lo común encontrar fragmentos de ollas sin cuello, al interior de la muestra analizada, 
Tabla 5. Sumario de formas y prevalencias de vasijas por unidad espacial.

Summary of vessel forms and frequencies per spatial unit.

\begin{tabular}{lll}
\hline \multicolumn{1}{c}{ Vasija } & \multicolumn{1}{c}{ Tamaño } & Prevalencia \\
\hline Olla sin cuello & Pequeño, mediano y grande & Grande \\
Cuenco & Mediano & Mediano \\
Jarra & Pequeño & Pequeño \\
Botella & Pequeño y mediano & Pequeño \\
Vaso & Pequeño, mediano y grande & Pequeño \\
Plato & Grande & Grande \\
\hline
\end{tabular}

Unidad espacial Basural

\begin{tabular}{lll}
\hline \multicolumn{1}{c}{ Vasija } & \multicolumn{1}{c}{ Tamaño } & Prevalencia \\
\hline Olla sin cuello & Pequeño, mediano y grande & Grande \\
Cuenco & Mediano & Mediano \\
Jarra & Pequeño & Pequeño \\
Botella & Pequeño y mediano & Pequeño \\
Vaso & Pequeño, mediano y grande & Pequeño \\
Plato & Grande & Grande \\
\hline
\end{tabular}

Unidad espacial Cuartos de Piedra

\begin{tabular}{lll}
\hline \multicolumn{1}{c}{ Vasija } & \multicolumn{1}{c}{ Tamaño } & \multicolumn{1}{c}{ Prevalencia } \\
\hline Olla sin cuello & Pequeño y grande & Pequeño \\
Cuenco & Pequeño y mediano & Pequeño \\
Jarra & Muy pequeño y pequeño & Muy pequeño y pequeño \\
Botella & Pequeño & Pequeño \\
Vaso & Ausente & Ausente \\
Plato & Pequeño y grande & Pequeño y grande \\
\hline
\end{tabular}

Unidad espacial Plataformas Tempranas

\begin{tabular}{lll}
\hline \multicolumn{1}{c}{ Vasija } & \multicolumn{1}{c}{ Tamaño } & \multicolumn{1}{c}{ Prevalencia } \\
\hline Olla sin cuello & Pequeño y grande & Grande \\
Cuenco & Mediano y grande & Grande \\
Jarra & Muy pequeño, pequeño y mediano & Mediano \\
Botella & Pequeño & Mediano \\
Vaso & Pequeño & Pequeño \\
Plato & Pequeño y grande & Pequeño y grande \\
\hline
\end{tabular}

Unidad espacial Correntera de Agua

\begin{tabular}{lll}
\hline \multicolumn{1}{c}{ Vasija } & \multicolumn{1}{c}{ Tamaño } & Prevalencia \\
\hline Olla sin cuello & Pequeño, mediano y grande & Grande \\
Cuenco & Pequeño, mediano & Mediano \\
Jarra & Muy pequeño, pequeño y grande & Mediano \\
Botella & Mediano & Mediano \\
Vaso & Mediano & Mediano \\
Plato & Ausente & Ausente \\
\hline
\end{tabular}

Unidad espacial Plataformas Tardías con manchas de hollín sobre la superficie. Las jarras pudieron ser utilizadas para almacenaje de los líquidos consumidos en los festines, desde donde pudieron ser vertidos en cuencos o probablemente vasos ${ }^{5}$. Sobre este punto en particular, es pertinente mencionar el modo en el cual se liba bebidas alcohólicas en algunas ceremonias en los Andes Centrales, en donde los líquidos son vertidos en un número reducido de vasos, los cuales son utilizados y reutilizados por el mismo grupo de personas. El registro arqueológico de esta actividad en particular arrojaría un número alto de contenedores (jarras, botellas, entre otros) y uno muy bajo de vasos.

A pesar de que no se han identificado un porcentaje alto de platos en la muestra analizada del basural, es interesante mencionar que los platos de tamaño grande son los de mayor ubicuidad en la muestra analizada (Figura 13). Los platos podrían haber sido utilizados para servir tipos especiales de alimentos y/o para ser consumidos por personas de singular importancia o distinción.

En el sitio de Cerro Blanco se han identificado formas cerámicas similares en contextos asociados a eventos de festín (Ikehara y Shibata 2005, Ikehara et al 2012). Con la diferencia de que en el basural del sector Wacheqsa no se identificaron vasijas asociadas al almacenamiento y fermentación de alimentos (Tabla 6). En Cerro Blanco, las vasijas para servir constituyen la mayoría identificada en los tres eventos de festín analizados, seguidos de las vasijas de cocina, lo cual es similar al patrón identificado en la muestra cerámica analizada en el basural del sector Wacheqsa (Ikehara y Shibata 2005; Tablas 3, 4 y 5). En el caso del basural originado por el desecho de materiales utilizados en festines, identificado en el sitio de Campanayuq Rumi, las vasijas para almacenar y/o fermentar (jarras) ocupan el primer lugar en incidencia relativa, seguida de las vasijas de servicio y de cocina (Matsumoto 2010: Tablas 6.3, 6.4 y 6.5). Con la excepción de un evento de Cerro Blanco, adscrito al Formativo Medio, el resto de eventos mencionados como ejemplos se dieron durante el Formativo Tardío. Es interesante contrastar el carácter funcional de vasijas asociadas a festines del período Formativo representado en la Tabla 6, con el de la época Inca (Tabla 7), en donde las principales diferencias se dan en el uso de los platos como instrumentos para cocinar y no para servir. Es sugerente que transcurridos casi dos mil quinientos años desde el inicio del Formativo Tardío hasta la época Inca, el carácter funcional 


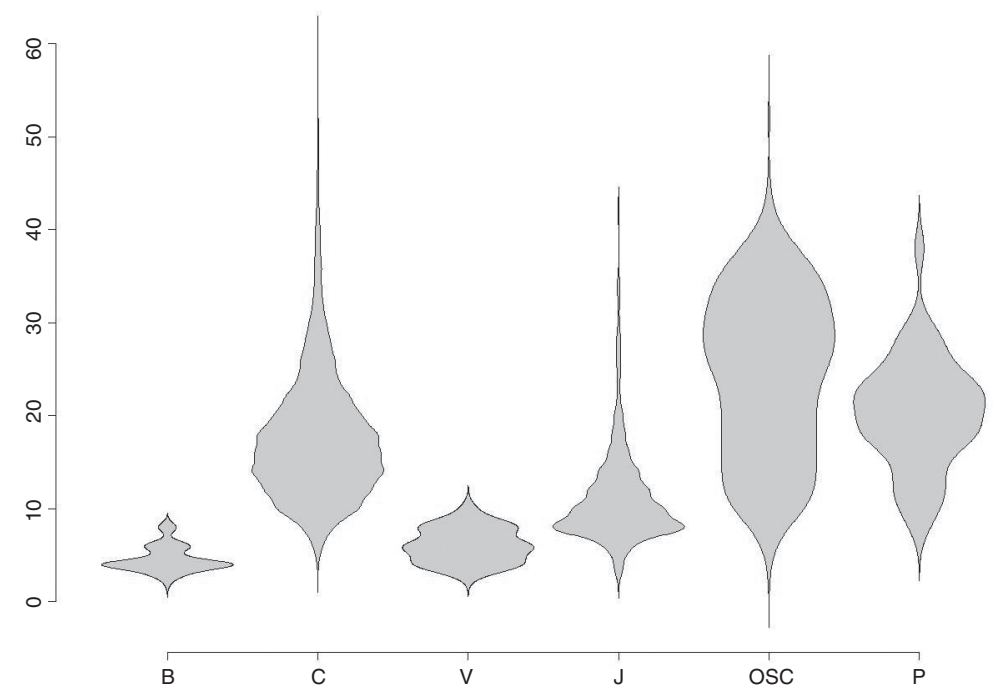

Figura 13. Diagrama de densidad estimada kernel unimodal de la cerámica del basural. Los valores en el axis $Y$ corresponden a los diámetros de las vasijas.

Unimodal kernel density estimation diagram of the ceramics in the midden. Values located on the $Y$ axis refer to vessel diameters.

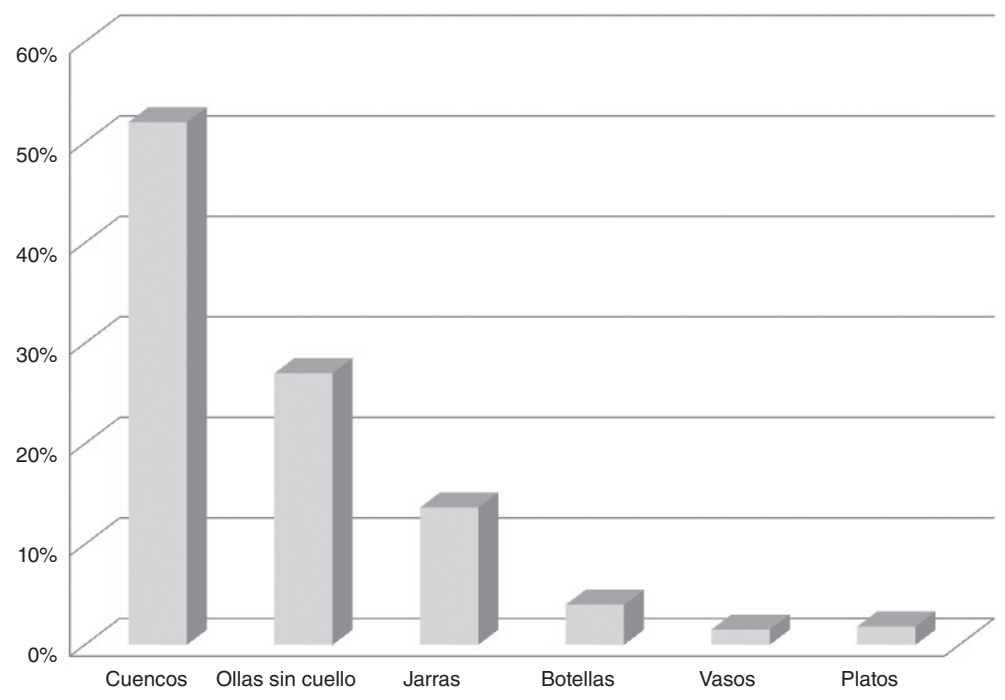

Figura 14. Distribución relativa de formas cerámicas en el basural.

Relative distribution of ceramic forms in the midden.

de las vasijas asociadas a festines no haya sufrido mayores modificaciones esenciales.

La presencia de vasijas para cocinar y servir es inusualmente alta en la unidad espacial Basural. Los cuencos de esta unidad forman el $84 \%$ de la muestra total de cuencos analizada, mientras que la presencia de ollas sin cuello de este basural llega al $74 \%$ de la muestra analizada.

\section{Restos de fauna}

El dato cerámico es más contundente cuando es cruzado con el volumen de restos de fauna recuperados, el cual es bastante alto comparado con el del resto de unidades espaciales, como se observa en la Figura 15 y las Tablas 8 y 9. Las pruebas $\mathrm{T}$ de los datos provenientes de las cinco unidades espaciales 
Tabla 6. Forma y función de vasijas asociadas a festines durante el Formativo Tardío (adaptado de Ikehara et al. 2012).

Forms and functions of feast-associated vessels during the Late Formative (adapted from Ikehara et al. 2012).

\begin{tabular}{ll}
\hline \multicolumn{1}{c}{ Forma } & \multicolumn{1}{c}{ Función } \\
\hline Vasijas para cocinar & Olla sin cuello, olla con cuello \\
Vasijas para almacenar y/o fermentar & Bateas, jarras \\
Vasijas para servir & Cuencos, platos, vasos, jarras \\
$\begin{array}{l}\text { Vasijas especiales para servir (énfasis } \\
\text { en la decoración) }\end{array}$ & Botellas \\
Funciones no determinadas & Compoteras, floreros. \\
\hline
\end{tabular}

identificadas indican que las medias de los depósitos excavados son significativamente diferentes. Estos resultados pueden ser considerados evidencia de un consumo sustancial de alimentos, lo cual se alinea con lo indicado por Mercer y Hayden quienes han sugerido lo siguiente en referencia a los restos de fauna como indicadores de festines, "los alimentos utilizados en festines, así como los festines en sí, pueden ser reconocidos por las copiosas sobras de comidas y muchos mayores desechos que lo normal [traducción del autor]" (Mercer 1985:100) y que "el desecho de festines ocurre en cantidades considerables en depósitos singulares [traducción del autor]" (Hayden 1995:138).

El basural está compuesto por estratos de características similares, en los cuales los restos de fauna son bastante cuantiosos. Sin embargo, esta evidencia en sí misma no es concluyente en relación con la ocurrencia de festines, pero cuando es cruzada con la evidencia cerámica ya mencionada, el argumento se hace más sólido. Se tuvo un cuidado especial al momento de realizar la excavación, a fin de segregar, de existir, materiales óseos humanos, los cuales no fueron encontrados en el basural. Análisis adicionales indicarán los animales que

Tabla 7. Forma y función de vasijas asociadas a festines durante la época Inca (adaptado de Bray 2003). Forms and functions of feast- associated vessels from the Inca Period (adapted from Bray 2003).

\begin{tabular}{ll}
\hline \multicolumn{1}{c}{ Forma } & \multicolumn{1}{c}{ Función } \\
\hline Olla con boca amplia, vasija con pedestal, plato & Cocina \\
Cazuela, cuenco, aríbalo, jarra con cuello amplio, kero & Servicio \\
Aríbalo, jarra con cuello estrecho, olla con boca amplia & Almacenamiento \\
Aríbalo & Transporte \\
\hline
\end{tabular}

fueron consumidos, sin embargo, dada la incidencia del consumo de camélidos en Chavín de Huántar, reportada en diversos estudios previos, es posible establecer la presunción educada, de que una gran cantidad se ubique dentro del rubro de los camélidos (Burger 1998; Miller y Burger 1995, 2000; Sayre 2010), lo cual ciertamente deberá ser corroborado con el análisis de una muestra estadísticamente significativa de la población recuperada.

\section{Parafernalia narcótica}

Instrumentos de hueso también estuvieron presentes en el basural. Entre ellos se identificaron pequeñas cucharas fragmentadas y tubos de diferentes tamaños (Figura 16). La presencia de tubos de hueso pulido y de pequeñas cucharas es interesante en la medida en que indican el consumo de sustancias psicoactivas durante los festines, "el instrumental necesario para la inhalación de polvos psicoactivos consiste en una pequeña tableta, un tubo inhalador, una cuchara y pequeños bolsos de cuero para guardar los polvos" (Torres y Repke 2006:11). De acuerdo con la evidencia etnográfica recuperada en Sudamérica y el Caribe, Torres y Repke indican que existen dos métodos generales de inhalación, el autoadministrado y el cooperativo. El autoadministrado requiere de inhaladores hechos de huesos de ave o de madera, los cuales pueden ser tubos simples o dobles, mientras que el modo colaborativo usualmente requiere de huesos largos de ave con el polvo dispuesto en un extremo, el cual es soplado por un individuo a las fosas nasales del usuario (Torres 2008; Torres and Repke 2006).

Es probable que la evidencia recuperada en el basural sugiera que el modo de consumo fue el autoadministrado y que el polvo inhalado estuvo derivado de la Anadenanthera como ha sido sugerido por Mesía, Torres, Repke y Rick (Mesia 2007; Rick 2006; Torres 2008; Torres y Repke 2006) y posteriormente por Burger (2011). Las semillas de Anadenanthera necesitan ser tostadas, luego la cascara es removida y el tejido interno molido hasta conseguir un polvo muy fino, los fragmentos sobrantes son molidos nuevamente y por último el polvo está listo para ser mezclado con cal a fin de ser consumida (Torres y Repke 2006). Instrumentos similares a los encontrados en el basural del sector Wacheqsa han sido recuperados en La Banda y han sido interpretados igualmente como evidencias del consumo de sustancias psicoactivas (Rick 2006; 


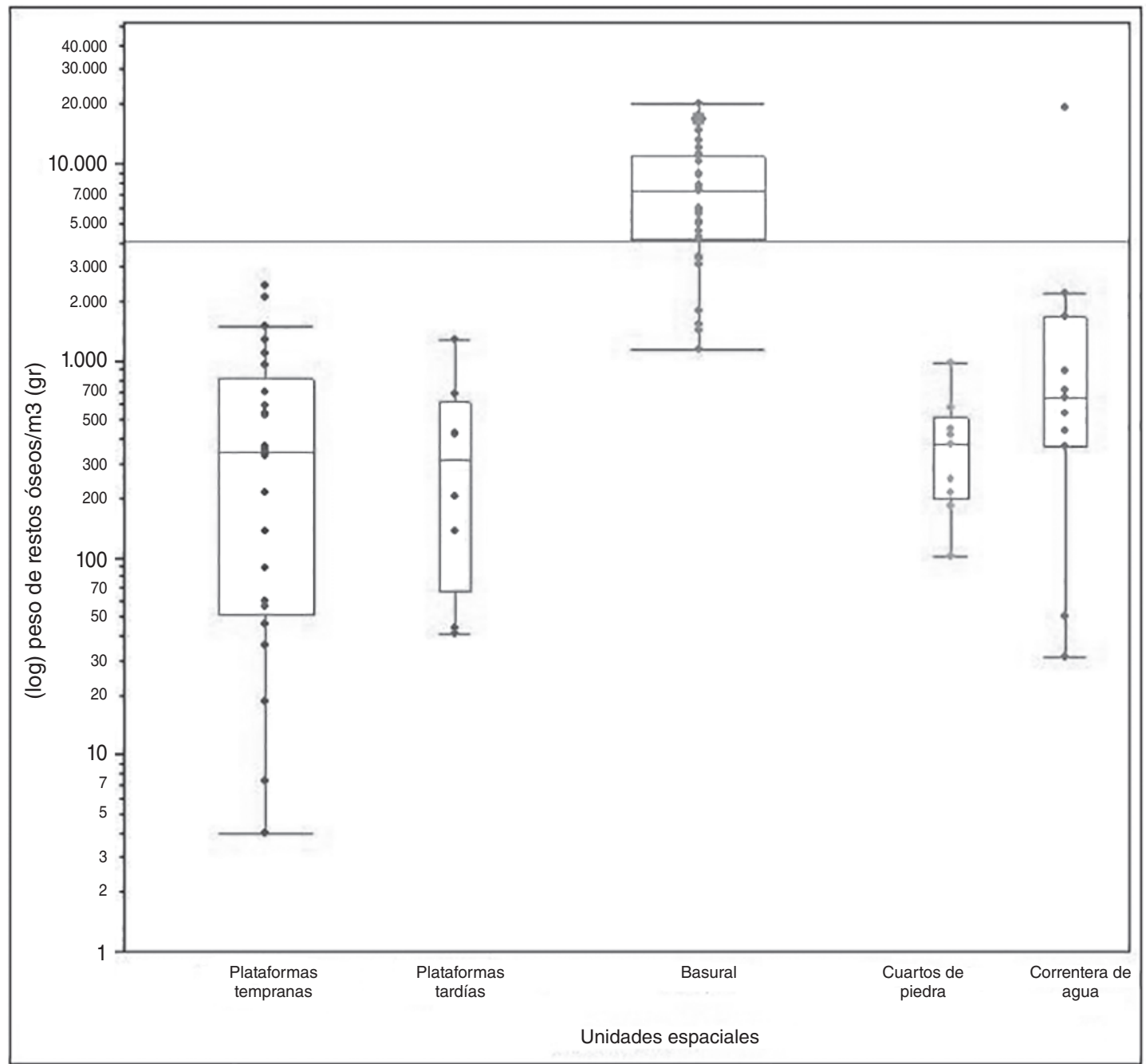

Figura 15. Densidad de fauna entre todas las unidades espaciales por metro cúbico.

Faunal densities among all spatial units.

Tabla 8. Test T de la matriz del umbral de la diferencia menos significativa. Los valores positivos muestran pares de medias estadísticas significativamente diferentes de los valores del peso de restos de fauna identificados en las cinco unidades espaciales del sector Wacheqsa.

T-test of the least significant difference threshold matrix. Positive values show pairs of statistically significant differences in the total weight of the faunal remains recovered in the five test units excavated in the Wacheqsa sector.

\begin{tabular}{lccccc}
\hline \multicolumn{5}{c}{$\begin{array}{c}1,98498 \\
\mathrm{t}\end{array}$} & $\begin{array}{c}\text { Alpha } \\
0,05\end{array}$ \\
\hline & Basural & Correntera de agua & Plataformas tempranas & Cuartos de piedra & Plataformas tardías \\
\hline Basural & $-2670,7$ & 2554,7 & 5657,6 & 4536,2 & 5236,1 \\
Correntera de agua & 2554,7 & $-4763,8$ & $-1917,2$ & $-2755,8$ & $-2167,4$ \\
Plataformas tempranas & 5657,6 & $-1917,2$ & $-2884,6$ & $-3974,7$ & $-3286,3$ \\
Cuartos de piedra & 4536,2 & $-2755,8$ & $-3974,7$ & $-4996,3$ & $-4419,2$ \\
Plataformas tardías & 5236,1 & $-2167,4$ & $-3286,3$ & $-4419,2$ & $-4079,5$ \\
\hline
\end{tabular}


Tabla 9. Test T, reporte de diferencias de la comparación del peso de restos de fauna identificados en las unidades espaciales del sector Wacheqsa. Mientras más reducido sea el valor de p-, mayor significativa será la diferencia estadística.

T-test results of the difference among the weight of faunal remains from the different excavation units in the Wacheqsa sector. The lower the $p$ value, the more significant the statistical difference.

\begin{tabular}{llrrrr}
\hline \multicolumn{1}{c}{ Unidad espacial } & \multicolumn{1}{c}{ Unidad espacial } & Diferencia & CL Inferior & CL Superior & Valor p- \\
\hline Basural & Plataformas tardías & 8683,948 & 5236,14 & 12131,76 & 0,0000026 \\
Basural & Cuartos de piedra & 8542,161 & 4536,17 & 12548,15 & 0,0000529 \\
Basural & Plataformas tempranas & 8437,329 & 5657,62 & 11217,04 & 0,0000026 \\
Basural & Correntera de agua & 6416,508 & 2554,74 & 10278,28 & 0,0013658 \\
Correntera de agua & Plataformas tardías & 2267,440 & $-2167,44$ & 6702,33 & 0,3127186 \\
Correntera de agua & Cuartos de piedra & 2125,653 & $-2755,82$ & 7007,13 & 0,3895406 \\
Correntera de agua & Plataformas tempranas & 2020,821 & $-1917,15$ & 5958,79 & 0,3109436 \\
Plataformas tempranas & Plataformas tardías & 246,620 & $-3286,33$ & 3779,57 & 0,8900858 \\
Cuartos de piedra & Plataformas tardías & 141,787 & $-4419,23$ & 4702,81 & 0,9509248 \\
Plataformas tempranas & Cuartos de piedra & 104,832 & $-3974,67$ & 4184,33 & 0,9594244 \\
\hline
\end{tabular}

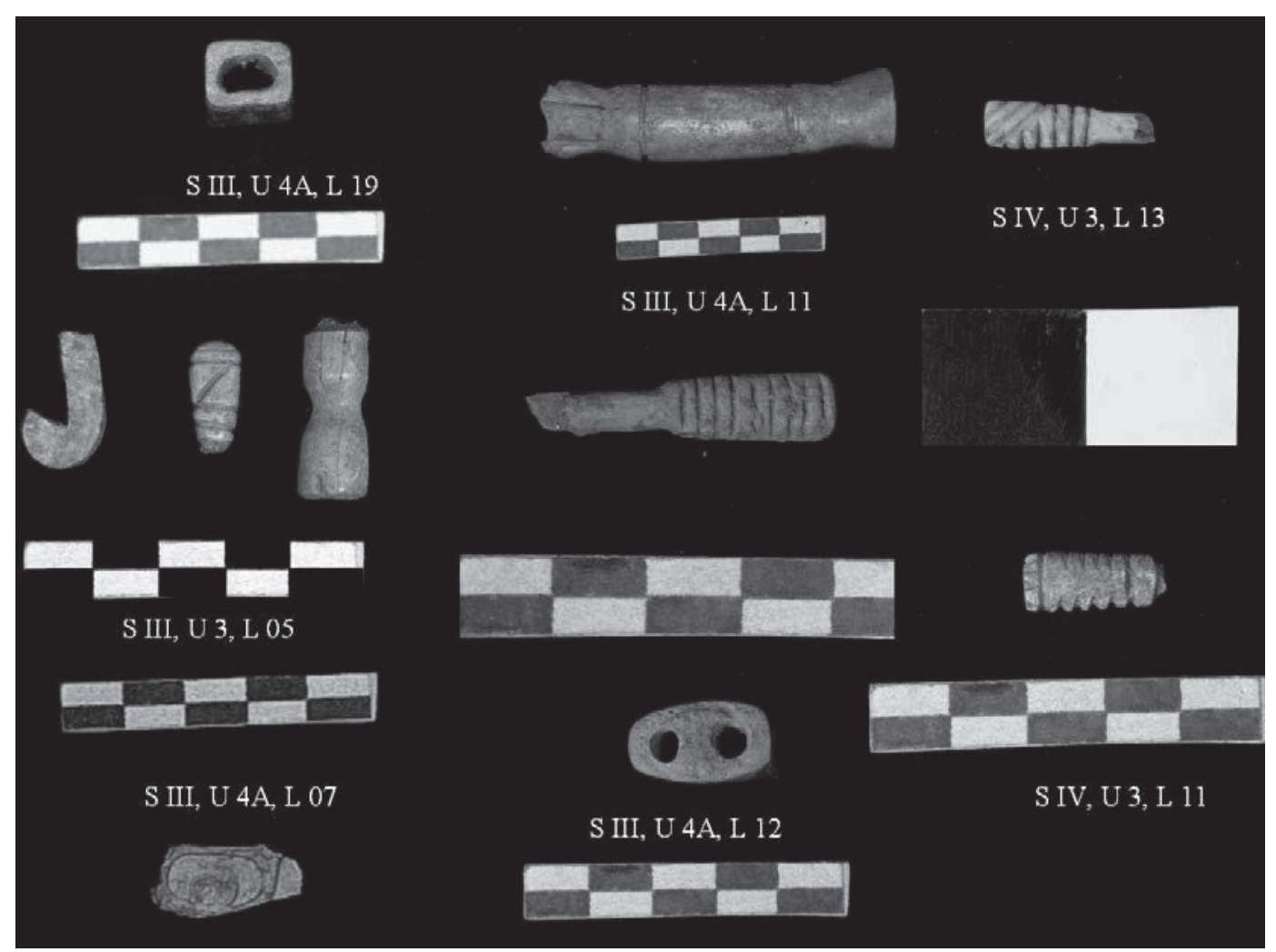

Figura 16. Artefactos de hueso posiblemente utilizados para la ingesta de sustancias psicoactivas.

Bone artifacts possibly used for consumption of psychoactive substances.

Sayre 2010). Del mismo modo, en el contexto ya mencionado de Campanayuq Rumi se han encontrado similares instrumentos, los cuales han sido interpretados como evidencias del probable consumo de alucinógenos "la parafernalia de artefactos de hueso utilizados con fines de inhalación indican claramente que las actividades rituales llevadas a cabo en conjunto con los festines incluyeron la inhalación de alucinógenos [traducción del autor]" (Matsumoto 2010:369).

Por otra parte, en un fragmento de vasija de servicio (Figura 17) se tiene la representación del cactus conocido como San Pedro (Trichocereus pachanoi), lo cual podría considerarse un indicador 
del consumo de San Pedro, planta que posee conocidas cualidades alucinógenas (Torres 2008). Representaciones de San Pedro son comunes en la cerámica del período Formativo de los Andes Centrales, y en Chavín de Huántar el cactus es endémico y está representado en la iconografía de la Plaza Circular del centro ceremonial (Figura 18).

\section{Elementos exóticos}

En el basural se han encontrado moluscos, aunque en cantidades mínimas, ya que se recuperaron tan solo seis fragmentos de Mesodesma donaceum. La presencia de moluscos en Chavín de Huántar se debió fundamentalmente a razones ceremoniales antes que nutricionales, en vista de que es costoso transportarlas desde la costa y mantenerlas frescas durante el viaje (Burger 1998). De acuerdo con Sheila Pozorski, es posible transportar moluscos frescos desde la costa hacia Chavín, si estos se mantienen en un ambiente salino y húmedo, lo cual hace que el transporte sea bastante oneroso (citada por Burger como comunicación personal en Burger 1998:242). El viaje desde la costa hacia Chavín puede ser realizado entre cuatro y siete días (Burger 1998), lo que permitiría a los moluscos permanecer frescos si se toman las precauciones ya mencionadas. La densidad

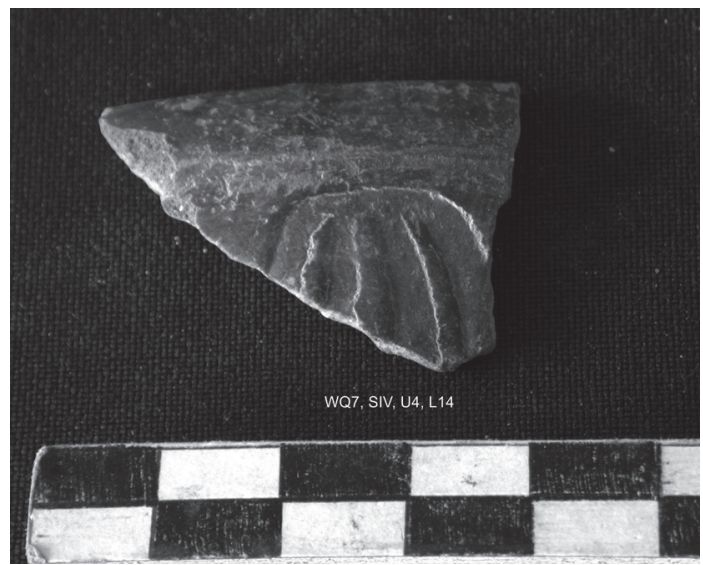

Figura 17. Fragmento de vasija de cerámica con representación del cactus San Pedro en la superficie.

Fragment of a pottery vessel with representation of the San Pedro cactus on surface.

tan baja de moluscos en el basural puede ser también explicada por la fragilidad de su consistencia. Grandes cantidades de desechos fueron arrojados al basural, los cuales sin duda alguna desintegrarían materiales frágiles, reduciendo las frecuencias de materiales a recuperar. Otra línea de evidencia que refuerza la presencia de moluscos como elementos rituales o consumidos por élites, está en el hecho de

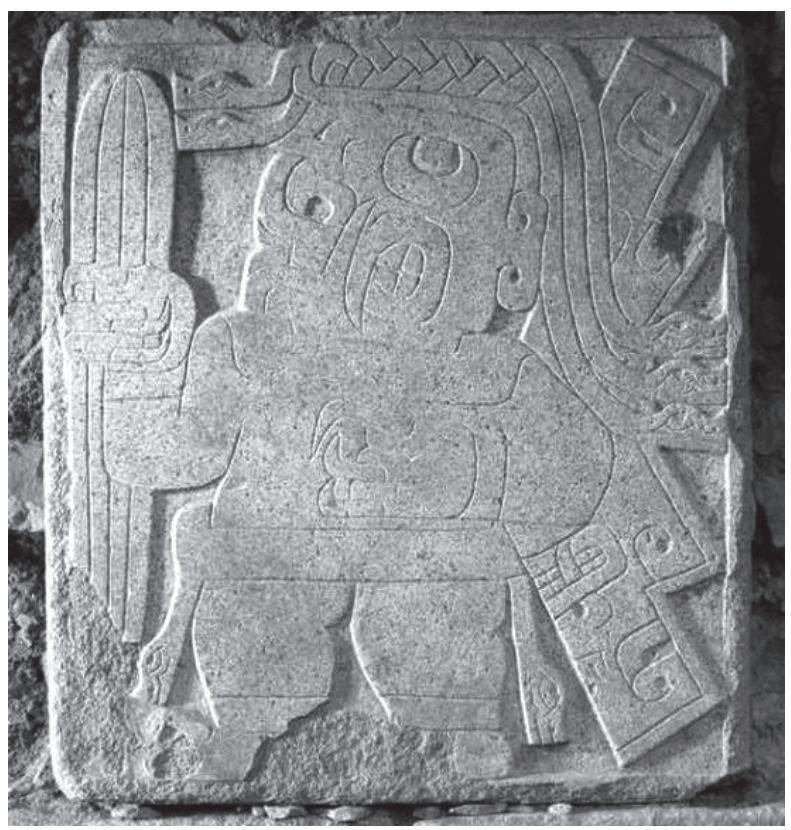

Figura 18. Laja ubicada en la Plaza circular del centro ceremonial. Personaje antropomorfo portando un cactus San Pedro.

Stone slab located at the sunken circular plaza of the ceremonial center with an incised anthropomorphic being holding San Pedro cactus. 
que $90 \%$ de la muestra de moluscos recuperada en excavaciones realizadas en contextos domésticos, proviene de unidades residenciales identificadas como pertenecientes a la élite (Burger 1984, 1988).

Ítems exóticos también incluyen a puntas de proyectil de cuarcita y cuentas de crisocola (Figuras 19a-b). Del mismo modo existe una cantidad pequeña de pendientes de hueso, probablemente utilizado alrededor del cuello (Figura 20a) así como un fragmento de un instrumento musical de viento (¿quena?) (Figura 20b), lo cual sugiere que la música podría haber formado parte de los festines. Si bien lo exótico no necesariamente es sinónimo de prestigio, no deja de ser algo especial o fuera de lo común, con el potencial de convertirse en un bien de prestigio de acuerdo con los intereses de las élites. Y el acceso a bienes fuera de lo común requiere de una inversión de recursos que pueden llegar a convertirlos en bienes de prestigio o lujo (Seki y Yoneda 2005). Es decir, todo bien exótico tiene el inherente potencial de convertirse en un elemento de prestigio. Como ha sido sugerido por otros autores (Seki y Yoneda 2005), estos valores (prestigio, lujo, entre otros) incorporados al bien exótico, tienen significados culturales e ideológicos ajustados al contexto particular (económico, político) en el cual se da el consumo de los mismos. ¿Son los bienes exóticos identificados en el basural del Sector

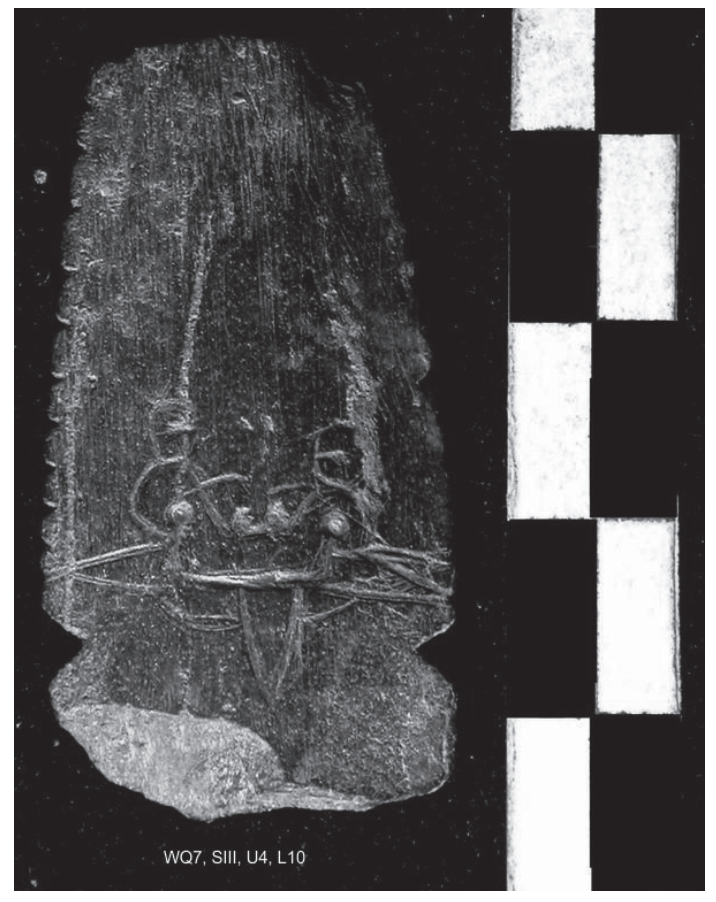

Figura 19a. Punta de cuarcita, con pedúnculo y borde aserrado. Sobre su superficie presenta el rostro inciso del personaje que aparece en la Estela Raimondi.

Stemmed quartzite projectile point with serrated edges bearing the incised face of the character that appears in the Raimondi Stelae on one surface.

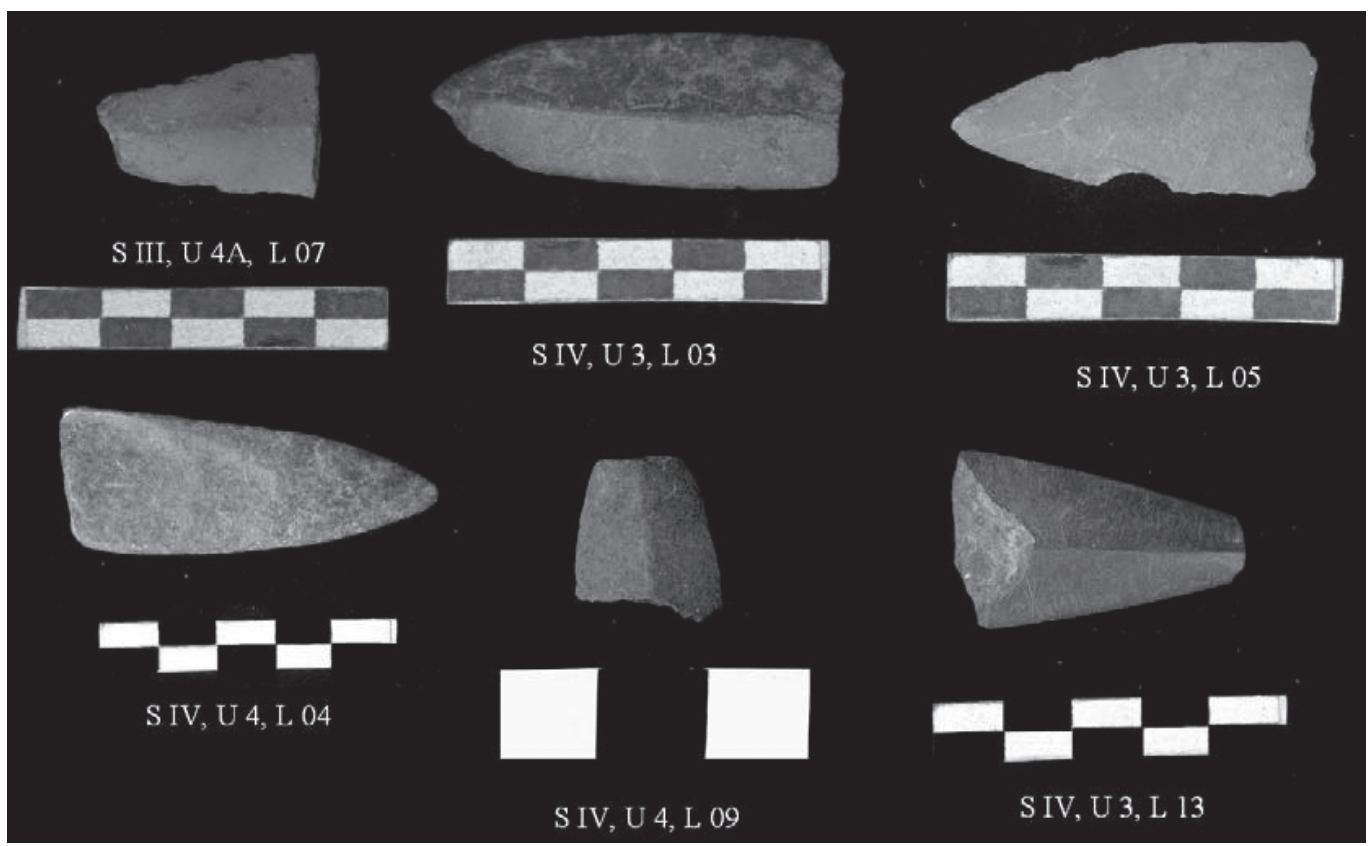

Figura 19b. Puntas de proyectil de cuarcita.

Quartzite projectile points. 

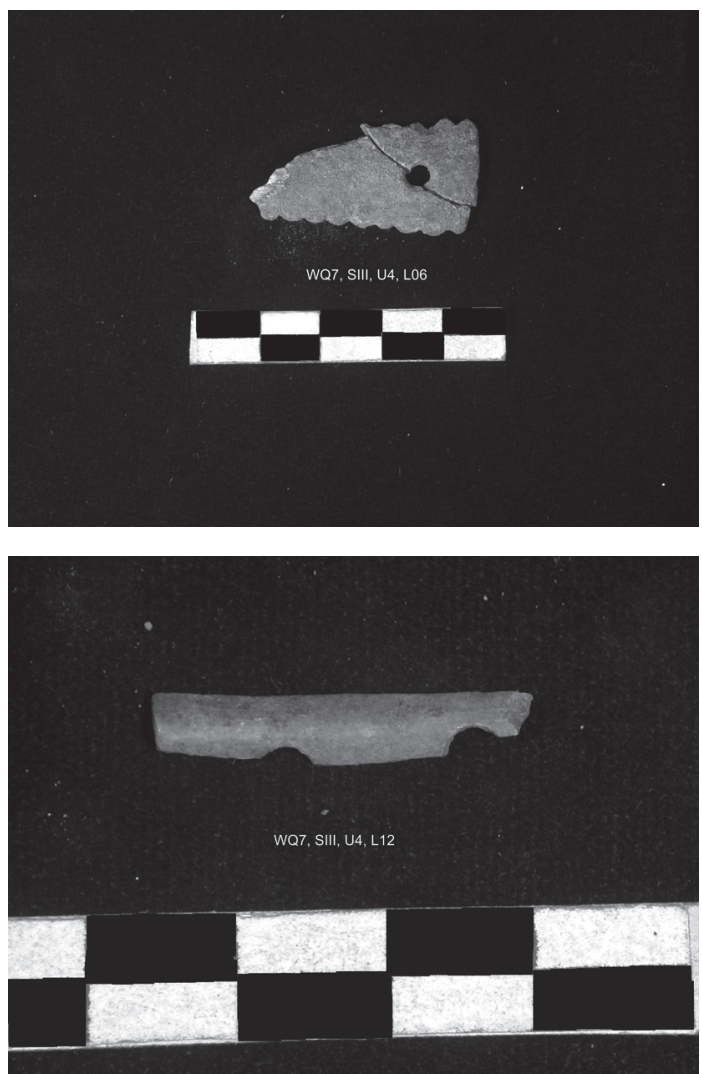

Figura 20 (a) Pendiente de hueso. (b) Fragmento de quena. (a) Bone pendant. (b) Quena fragment.

Wacheqsa, elementos de prestigio? La distribución de los moluscos asociada a consumo de unidades domésticas de élite (Burger 1984, 1988), así como lo costoso de su transporte hacia el Callejón de Conchucos así lo sugiere. La probable presencia de talleres especializados en la producción de artefactos de hueso y crisocola en La Banda (Rick 2005, 2008; Sayre 2010) y en el Sector Wacheqsa (Mesia 2007), así como la ausencia de canteras de este material en el Callejón de Conchucos, y la no muy extendida presencia de este bien en los diversos contextos excavados en Chavín de Huántar, sugiere que este probablemente haya sido también un bien exótico de prestigio. Es necesario indicar que en la sierra norte, en el sitio de Kuntur Wasi, se han recuperado contextos funerarios de élite asociados a elementos de crisocola (Onuki, 1995; Seki y Yoneda 2005).

\section{Restos macrobotánicos}

Se tomaron muestras para flotamiento las que fueron procesadas y analizadas por Matt Sayre (Sayre
2010). El basural presenta la mayor diversidad de semillas que otros sectores del centro ceremonial. Se han identificado restos de maíz, gramíneas, cucurbitáceas, tuberosas, legumbres y Chenopodium, entre otros (Tabla 10). La presencia de Zea mays podría indicar su uso en la preparación de chicha, comúnmente asociada a festines a lo largo de la prehistoria de los Andes Centrales en general y en el período Formativo en particular. En los sitios de Cerro Blanco (Ikehara y Shibata 2005; Ikehara et al. 2013) y Campanayuq Rumi (Matsumoto 2010, 2012) se ha identificado la presencia de Zea mays asociado a festines durante el Formativo Tardío, período en el cual se formó el basural del sector Wacheqsa. Tanto Ikehara et al. como Matsumoto argumentan que esta presencia se debe fundamentalmente al consumo de chicha de maíz fermentado consumido en los banquetes identificados en ambos sitios. Se ha planteado la posibilidad de que en Chavín de Huántar, la planta Zea mays fue utilizada primariamente en la preparación de chicha de maíz fermentado (Burger y Van Der Merwe 1990), brebaje asociado a festines a lo largo de la prehistoria y etnografía andina (Murra 1960). La presencia de ollas sin cuello de gran tamaño en el basural es sugerente en este sentido, ya que

el maíz no solamente fue consumido cocido o tostado, sino también preparado en forma de licor o 'chicha', aunque todavía sólo tenemos pruebas hipotéticas existe una relación entre las ollas y las vasijas grandes con la producción de chicha". (Seki y Yoneda 1995:125. Énfasis del autor).

Tabla 10. Restos macrobotánicos identificados en el basural (adaptado de Sayre 2010).

Macrobotanical remains identified in the midden (based on Sayre 2010).

\begin{tabular}{lc}
\hline Especie & $\mathrm{n}$ \\
\hline Parenchyma & 17 \\
Fabaceae & 16 \\
Poaceae & 2 \\
Zea mays & 4 \\
Chenopodium & 2 \\
Verbena sp. & 2 \\
Mantaganaceae & 3 \\
Curcubitaceae & 2 \\
Malvaceae & 1 \\
Desconocido & 3 \\
Inidentificable & 3 \\
\hline
\end{tabular}


Por otra parte se ha comprobado el uso de ollas sin cuello en la producción de chicha de maíz fermentado para el sitio de Cerro Blanco así como el incremento del uso de ollas sin cuello y cuencos de gran tamaño asociados al aumento del consumo de maíz (Ikehara et al. 2013). En el basural del Sector Wacheqsa se da un notorio incremento en el uso de ollas sin cuello de gran tamaño en relación con el resto de unidades espaciales que conforman este sector, siendo particularmente interesante la distribución de ollas sin cuello del Formativo Medio y del Formativo Tardío, en donde se da un cambio sumamente pronunciado en el tamaño de estas vasijas (Figura 21) (Mesía 2007, 2012). Hasta cierto punto esto estaría en concordancia con la hipótesis del uso intenso del maíz a partir del Formativo Tardío (Ikehara et al. 2013; Kaulicke 2010; Seki y Yoneda 1995).

Por otro lado, la gran cantidad de frejoles (Fabaceae) así como la presencia de semillas de calabaza (Cucurbitaceae) indicaría que las actividades que originaron los desechos que forman parte del basural tuvieron formas de preparación y almacenamiento de alimentos distintos al patrón registrado en otros sectores de Chavín de Huántar (Sayre 2010). En tal sentido, dada la evidencia existente es probable que durante los festines, el consumo de chicha de maíz fermentado haya estado
Diámetros de bordes de ollas sin cuello

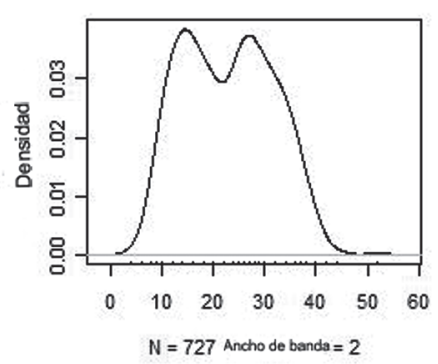

Diámetros de bordes de ollas sin cuello de las Plataformas Tardias

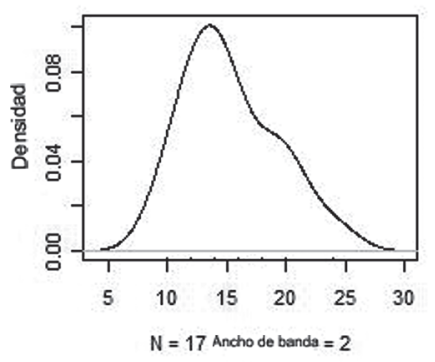

Diámetros de bordes de ollas sin cuello del Formativo Tardio (800 - 500 a.C.)

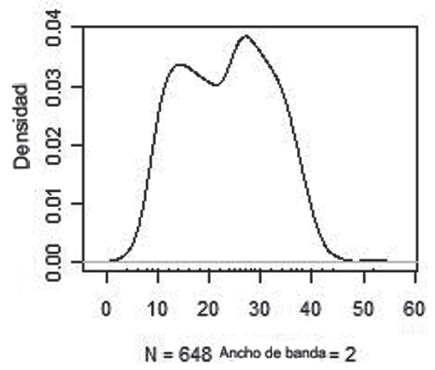

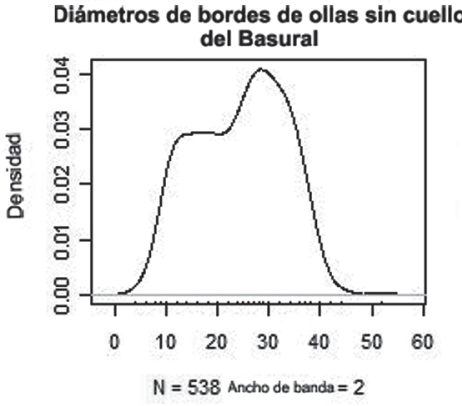

Diámetros de bordes de ollas sin cuello de las Plataformas Tempranas

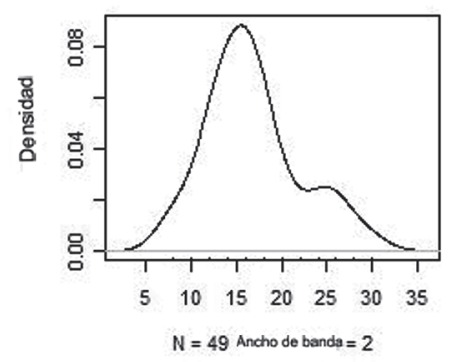

Diámetros de bordes de ollas sin cuello del Formativo Medio (1200 - 800 a.C.)

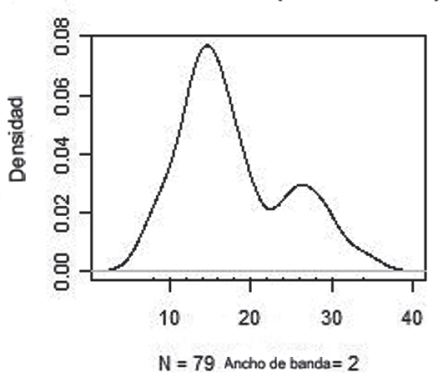

Diámetros de bordes de ollas sin cuello

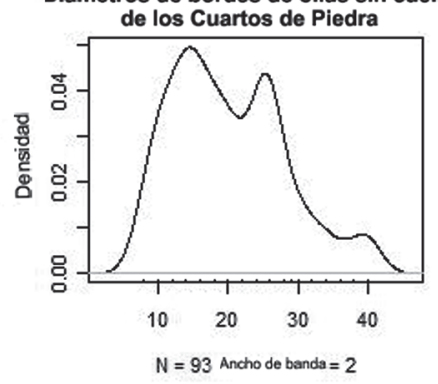

Diámetros de bordes de ollas sin cuello de la Correntera de Agua

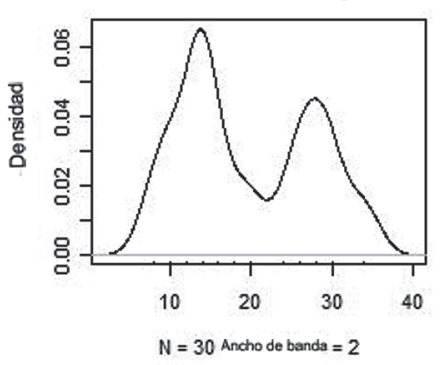

Figura 21. Distribución de diámetros de ollas sin cuello por unidad espacial y período (tomado de Mesía 2012). Rim diameter distribution of neckless jars by spatial unit and period (taken from Mesía 2012). 
acompañado de quinua o cañiwa (Chenopodium), frejoles (Fabaceae), papas u ocas (Solanaceae) y calabazas, además de carne de camélidos, y otros alimentos aún no identificados. La parénquima es un tejido de almacenamiento del interior de una tuberosa o de otro órgano de almacenamiento subterráneo. En los Andes Centrales proviene en su mayoría de papas (Solanum sp.) y de la oca (Oxalis tuberosa).

Fragmentos de frisos, muros, pisos y columnas

Si examinamos las modalidades cerámicas, parafernalia narcótica, restos de fauna, restos macrobotánicos e ítems exóticos en conjunto, la cantidad y calidad sugiere que el basural se originó mediante el desecho de materiales provenientes del consumo supracomunal de alimentos, bebidas y muy probablemente de sustancias psicoactivas, "los festines, de acuerdo a su propia naturaleza, producen cantidades copiosas de desechos singulares en los lugares donde ocurren, y estos lugares están a menudo asociados a estructuras rituales notables" (Dietler y Hayden 2001:9). En aislamiento, estos indicadores no parecen ser lo suficientemente robustos como para proponer de manera inequívoca la presencia de festines supracomunales en Chavín de Huántar, pero en conjunto, provenientes de depósitos estratigráficos rigurosamente excavados, proveen de los elementos necesarios para apoyar la citada proposición.

Sin embargo, existe un conjunto de materiales que podrían no encajar claramente en el argumento de festines supracomunales: grandes cantidades de fragmentos de columnas, muros, y pisos, hechos de arcilla y en algunos casos con evidencias de fuerte combustión (Figuras 22a, b) incluyendo el fragmento de un friso de arcilla (Figura 22c). Estos fragmentos están presentes en el basural, con una media de 99,96 fragmentos por metro cúbico. Dadas sus dimensiones, provinieron de grandes estructuras, finamente enlucidas con pintura blanca y roja. Tello encontró fragmentos similares frente al Edificio A, los cuales al parecer fueron parte de la fachada del mencionado edificio, aunque él planteó que fueron los restos de un gran incendio que asoló al centro ceremonial

Frente a la escalera [escalera sur de la fachada del Edificio A] aparecen fragmentos abundantes de arcilla quemada muchos de ellos muy quemados y amorfos, sugiriendo que la combustión fue bastante alta y que no corresponden a las técnicas de preparación del enlucido de muros mediante el fuego. Es muy probable que un fuego intencional o no intencional fuera el responsable de las evidencias de fuego en estos materiales (Tello 1940:50).

Una fracción de los fragmentos de piso y muros muestran signos de vitrificación sobre sus superficies (Figura 22b), sugiriendo altas temperaturas de combustión. ¿Cómo podrían estos elementos relacionarse con los festines? ¿Podrían ser parte de las estructuras en donde ocurrieron los festines? ¿Existió alguna clase de ritual destructivo como parte de los festines? $\mathrm{O}_{¿}$ estos materiales provienen de otra clase de contextos?

La destrucción ceremonial de vasijas ha sido registrada para el sitio de Conchopata, ubicado cronológicamente como parte del período del Imperio Wari (700-1.100 d.C.), en donde vasijas ceremoniales fueron destruidas y luego enterradas o desechadas, como parte de festines supracomunales (Cook y Glowacki 2003). Si extendemos esta analogía a los fragmentos de arquitectura mencionados líneas arriba, ¿podría destruirse parte de la arquitectura en la cual se desarrollaron los festines, luego de la conclusión de los mismos? Un caso que es pertinente mencionar, es el de Campanayuq Rumi, en Ayacucho (Matsumoto 2010, 2012). En este sitio se registraron dos contextos asociados a festines, uno de los cuales consistió en un depósito de basura acumulada por eventos continuos, llevados a cabo en una plataforma cercana. En este contexto se identificaron del mismo modo restos de frisos quemados de arcilla, "estos fragmentos solo se preservaron debido a que fueron parcialmente quemados después de haber caído del muro. La quema no fue intencional y se originó al desechar los frisos con otra basura procedente de banquetes ceremoniales en P2 [traducción del autor]" (Matsumoto 2010:364). El basural originado por el desecho de materiales asociados a banquetes en Campanayuq Rumi está compuesto por parafernalia narcótica, copiosos restos de fauna animal, cerámicas asociadas al consumo y preparación de alimentos, así como bienes exóticos y/o de prestigio (artefactos de oro, artefactos óseos, una cuenta de piedra verde, puntas de obsidiana) (Matsumoto 2010, 2012), lo cual es semejante a la composición del basural recuperado en el sector 


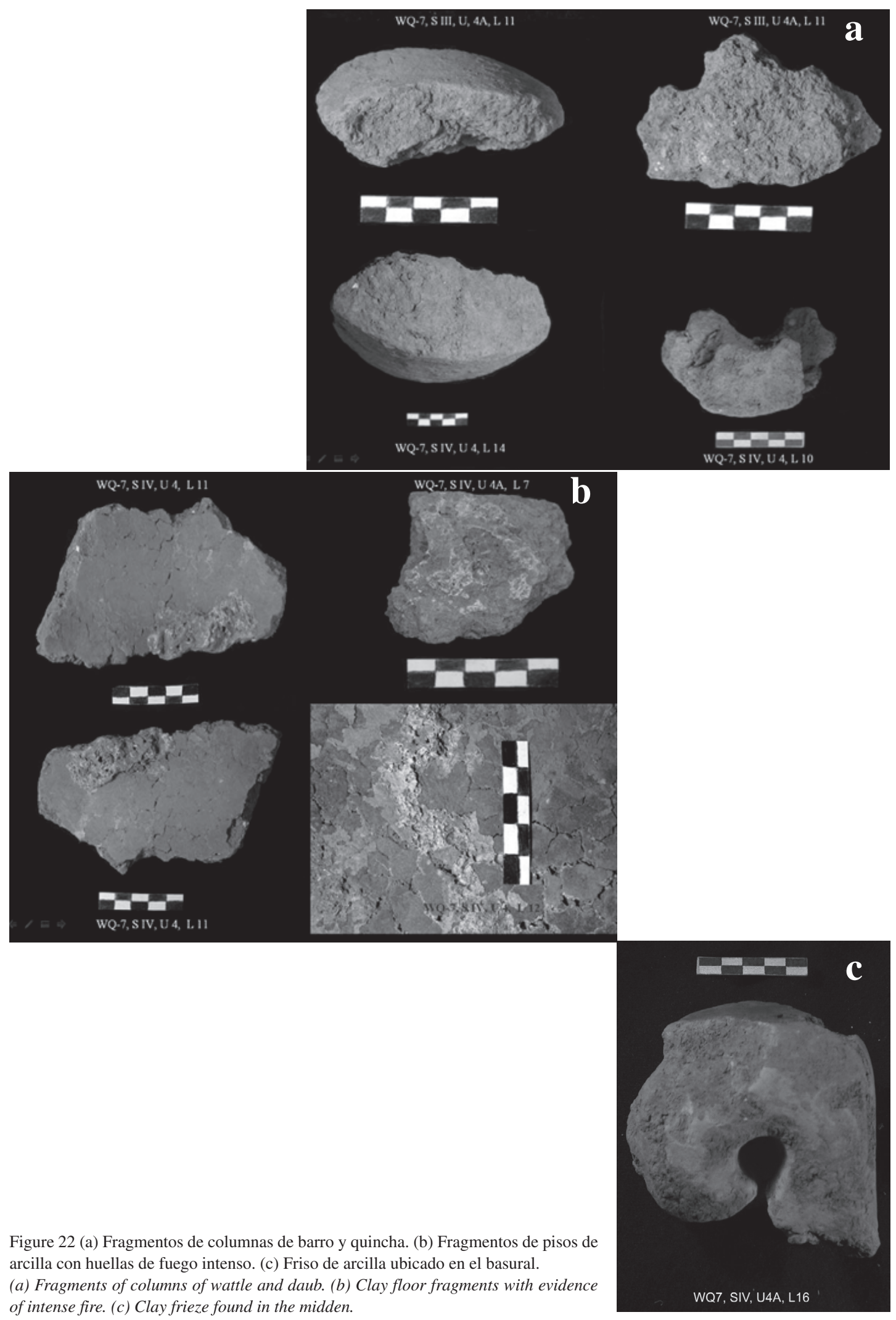


Wacheqsa de Chavín de Huántar. El otro contexto está asociado a la remodelación de un piso, el cual ha sido interpretado como relacionado con un evento de trabajo comunal (Matsumoto 2010).

Por otra parte, en Sajarapataq, Matsumoto y Tsurumi han identificado contextos de festines, uno de ellos asociado a la construcción de un nuevo piso (Fase Sajarapataq 1), el cual cubrió un viejo piso en una estructura circular, sobre el cual los restos de los banquetes fueron solo parcialmente removidos, dejando sobre la superficie del piso los fragmentos de las vasijas utilizadas en el festín, así como cenizas que dan cuenta de eventos de combustión. Durante la Fase Sajarapataq 2 se encontró un contexto similar (con la diferencia de que no fue cubierto por piso alguno), el cual de acuerdo a los autores indicaría que los festines estarían asociados a la renovación de la arquitectura ceremonial (Matsumoto y Tsurumi 2010). A diferencia del caso del Sector Wacheqsa en Chavín de Huántar, y del primer ejemplo de Campanayuq Rumi, no se han identificado el lugar en el cual se depositaron los desechos producto de estas actividades.

Es probable que la presencia de fragmentos de pisos, muros y frisos, en basurales asociados a banquetes, esté relacionada efectivamente con eventos de destrucción, remodelación y construcción de espacios arquitectónicos, relacionados con formas de trabajo comunal (Hayden 2001; Vega Centeno 2007), o que sin estar asociados a trabajos comunales, estos eventos de destrucción, construcción y remodelación, sean más una forma más de exhibición de poder por parte de las autoridades del centro ceremonial. La renovación arquitectónica (la cual pudo ser múltiple y simultánea en un sitio de la envergadura de Chavín de Huántar) probablemente haya sido otra forma de materialización visible de poder y autoridad. Después de todo la teatralización del poder es otra de las formas de exhibición y reafirmación de autoridad (Rick 2006, 2008).

A juzgar por la evidencia existente, la hipótesis de la ocurrencia de festines supracomunales en Chavín de Huántar es viable. Las modalidades cerámicas identificadas, la alta densidad de restos de fauna, la evidencia de consumo de sustancias psicoactivas, así como los materiales exóticos ya descritos, examinados en conjunto y no independientemente, apuntan hacia la ocurrencia de festines como la explicación más plausible.

\section{Festines y Poder}

El registro arqueológico recuperado en el basural sugiere el consumo supracomunal de alimentos en Chavín de Huántar. La ocurrencia de festines supracomunales en Chavín de Huántar no debería llamar la atención, dada la extensión del sitio y la energía invertida en su arquitectura, arte y modificación topográfica que tuvo lugar allí (Contreras 2007, 2009; Kembel 2001, 2008; Rick 2008). Los festines en Chavín de Huántar tienen mucha relación con las estrategias de poder y actividades corporativas auspiciadas en Chavín durante el Formativo Andino. El poder no está enteramente relacionado con la fuerza, en tanto que es una compleja mezcla de derechos adquiridos por tradición, méritos individuales, carisma, herencia, persuasión, y otros factores, en donde la fuerza se hace presente cuando los cálculos entre costo y los beneficios de la resistencia son negativos (Phillips y Sebastian 2004), por lo que los festines son ejemplos del ejercicio de poder sin uso de coerción física.

En Chavín de Huántar existen lugares que pudieron ser utilizados como escenarios de banquetes como la plaza cuadrada localizada frente al Edificio A, entre los Edificios E y F, disposición en forma de U que recuerda a los complejos cívicos ceremoniales con planta en U de la costa central, la cual pudo contener al menos 1.500 personas (Burger 1992). Otro probable escenario es la plaza circular ubicada frente al Edificio B, entre los Edificios A y $\mathrm{C}$, siguiendo del mismo modo el patrón en U ya mencionado; de acuerdo con la secuencia de crecimiento vigente, estas dos plazas fueron construidas como parte de la fase arquitectónica Blanco y Negro (Kembel 2001) fechada entre 800 y 550 a.C. Un tercer posible escenario es una probable plaza, hallada recientemente por John Rick, al norte del Edificio D, la cual pudo ser construida durante la fase Blanco y Negro (John Rick, comunicación personal, 2011). La fase Blanco y Negro fue un momento arquitectónico en el cual se dieron los mayores esfuerzos constructivos en la prehistoria del centro ceremonial, entre ellos, la modificación del curso del río Mosna a fin de poder contar con el espacio necesario para la construcción de la plaza cuadrada (Kembel 2001; Kembel y Rick 2004; Rick 2005, 2008). Evidencia adicional concerniente al desplazamiento del río fue recogida por Contreras en excavaciones realizadas al sur del Edificio E (Contreras 2007, 2009). 
A diferencia de la plaza cuadrada que está en un espacio abierto, la plaza circular se encuentra ubicada en un espacio más privado (lo cual se ve reforzado por sus $21 \mathrm{~m}$ de diámetro). El aislamiento visual de la plaza es reforzado por la ubicación del piso de la plaza, a dos metros por debajo de los atrios que la flanquean. La pared lateral de la plaza está cubierta de lajas de piedra, grabados con diseños antropomorfos y zoomorfos que representan el mundo religioso de Chavín de Huántar, creándose un espacio restricto, aislado, pero al mismo tiempo sagrado, en donde el resto del mundo fuera de la plaza formaba parte de otro plano real; esta plaza posiblemente tuvo capacidad de albergar al menos a 500 personas (Burger 1992).

Estas plazas han sido interpretadas como escenarios de ceremonias adscritas a los rituales escenificados en Chavín de Huántar (Burger 1992; Kembel 2001; Kembel y Rick 2004; Lumbreras 1989, 1993, 2007; Rick 2005, 2008; Tello 1960) y pudieron ser también lugares en los cuales se desarrollaron festines en el centro ceremonial. Es importante anotar que durante la fase Blanco y Negro hubo un énfasis hacia la construcción de espacios abiertos en lugar de espacios pequeños, como galerías

el cambio a la fase Blanco y Negro, con sus plazas, terrazas y montículos laterales con escalinatas, representa un cambio, enfatizando la necesidad de crear espacios abiertos lo suficientemente amplios como para albergar la mayor cantidad de gente posible (Kembel 2001:223. Énfasis del autor) [traducción del autor].

Esto sugiere la posibilidad de la ocurrencia de otras plazas, aún no descubiertas, en el centro ceremonial, lo cual no debería llamar la atención, dada la enorme complejidad arquitectónica del sitio.

La plaza circular estuvo flanqueada por los atrios norte y sur, en cuyos interiores se ubicaron las galerías Ofrendas y Caracolas respectivamente. La primera fue el lugar en el cual se depositaron 681 vasijas cerámicas, acompañadas de restos de alimentos, probablemente bebidas también, así como moluscos y artefactos de piedra, madera y hueso (Lumbreras 1989, 1993, 2007). En tanto, en la segunda galería mencionada se encontraron 20 trompetas de Strombus galeatus, con evidencias de uso intenso, probablemente como parte de las ceremonias llevadas a cabo en el centro ceremonial (Rick 2005). En la galería Ofrendas solamente se encontraron dos vasijas janabarroides mientras que las 679 vasijas restantes (99,7\% de la población total de vasijas encontradas en la galería) son representativas de estilos foráneos y locales religiosos. En el basural del sector Wacheqsa, gran parte de la cerámica presenta las típicas características janabarroides, como los círculos estampados, círculos concéntricos estampados, círculos estampados con punto central, diseños en forma de $\mathrm{S}$ estampados, diseños que dominan casi toda la cerámica recuperada en este contexto, mientras que los diseños relacionados con la iconografía representada en la arquitectura del centro ceremonial, o de los estilos identificados en la galería Ofrendas, no son muy ubicuos. La presencia de cerámicas severamente cargadas con contenido religioso y la presencia de cerámicas al parecer provenientes de las afueras de Chavín de Huántar, además de la casi ausencia de cerámica janabarroide en esta galería, sugiere que la cerámica encontrada en el basural fue de una naturaleza muy distinta a la ubicada en Ofrendas. El espacio arquitectónico en el cual se encuentra la plaza circular, aparentemente reviste de una naturaleza sacra, mucho mayor que el emplazamiento de plaza cuadrada. La cerámica janabarroide no es común en contextos religiosos en Chavín, considerando que la única evidencia de contextos religiosos in situ en Chavín proviene de las galerías Ofrendas y Caracolas. La densidad muy baja de cerámicas janabarroides en estas galerías sugiere que esta cerámica tenía una naturaleza o significado diferente a aquella representada por el resto de estilos identificados en ellas, las cuales presentan diseños de naturaleza antropomorfa, zoomorfa e incluso fitomorfa (Lumbreras 1998, 2003, 2007). A pesar de que la plaza cuadrada puede ser considerada como un área ceremonial, la diferencia de tamaño en relación con la plaza circular, sugiere que no todos los asistentes a las ceremonias realizadas en la plaza cuadrangular fueron permitidos de ingresar a la plaza circular.

La probable plaza recientemente encontrada se encuentra cerca del basural y fuera del núcleo monumental, a diferencia de las plazas ya mencionadas. Esta ubicación podría explicar por qué no existen en el basural elementos similares a los encontrados en Ofrendas y Caracolas, lo cual implicaría que las plazas construidas durante la fase arquitectónica Blanco y Negro pudieron ser utilizadas para diversos 
propósitos con acceso o destinados a diferentes grupos sociales, tal vez incluso de modo simultáneo. La posibilidad de que las tres plazas hayan sido utilizadas simultáneamente como escenarios de festines supracomunales es plausible dada la probabilidad que existieran jerarquías de festines dirigidos distintos grupos (Figura 23). Es necesario indicar la posibilidad de la existencia de otras plazas, lo cual ampliaría grandemente la jerarquía de festines y de los grupos participantes en ellos. En este contexto, los festines son evidencia de desigualdad social (Whalen y Minnis 2004), como se observa en los sitios de Paquime, en la zona norcentral de México (Phillips y Sebastian 2004) y Huambacho (Chicoine 2011) e incluso en los centros cívicos ceremoniales con planta U como Cardal, en donde las plazas circulares se encuentran fuera del núcleo ceremonial (Burger 2000; Burger y Salazar-Burger 1991). En Chavín se encontrarían diversos estratos o niveles de festines, en donde algunos estuvieron abiertos para todos, otros limitados a unos cuantos e incluso restringidos tan solo a una élite privilegiada. En Huambacho, los festines sirvieron como mecanismos para legitimar la desigualdad en un período de "intensa competición intercomunal [traducción del autor]"(Chicoine 2011:433), en Cerro Lampay, los festines sirvieron como mecanismos para mantener el poder en un contexto de control limitado por parte de la élite (Vega-Centeno 2007), en Chinchawas sirvieron como un mecanismo para movilizar fuerza de trabajo (Lau 2002), en Cerro Blanco como un instrumento de cohesión social (Ikehara y Shibata 2005) mientras que en Chavín, los festines se constituyeron en un mecanismo de propaganda en un contexto en donde la competición excedió el nivel local. Esta idea básica pudo ser materializada en festines de diverso alcance, dirigida a diversas audiencias.

¿Por qué las autoridades de Chavín invirtieron recursos en la organización de festines? Los centros ceremoniales que poblaron los Andes Centrales durante el Formativo Tardío compartieron un conjunto básico iconográfico que ha sido caracterizado como chavinoide. Burger ha sugerido una interacción de tipo peer polity entre centros ceremoniales, mientras que Kembel y Rick argumentan a favor de una condición competitiva entre los centros ceremoniales de este período (Burger 1988; Kembel y Rick 2004; Rick 2005). La competición es uno de los tantos modos en el cual la interacción peer polity puede manifestarse (Renfrew y Cherry 1986). La razón de este proceso competitivo descansa en la necesidad de adquirir el prestigio necesario para la supervivencia del sistema de creencias auspiciadas por las autoridades. El prestigio es reputación, la cual es internalizada por un grupo social, el cual desarrolla una aceptación o rechazo hacia dicho sistema de creencias que está materializado en el centro ceremonial que posee este prestigio, "competir por prestigio consiste en enfrentarse por un continuo y público reconocimiento [...] es equivalente a competir por personas, fuerza de trabajo, poder y apoyo" (Clark y Blake 1996:20). Es importante mantener el prestigio, tanto como fin político -ya que permite que las autoridades mantengan sus posiciones de privilegio- y como un fin evolutivo o de supervivencia del sistema, ya que permite la vigencia de este, el cual sirve de fundamento del poder político, social y económico de las élites. Considerando los límites cronológicos del centro ceremonial de Chavín de Huántar (1.200-500 a.C), es probable que en sus fases iniciales (1.200-800 ANE), los festines hayan servido como uno de los instrumentos utilizados para crear autoridad, mientras que durante la fase de apogeo del centro (800-500 ANE), los festines podrían haber servido para reafirmar esta autoridad, mantenerla y reproducir las ya existentes condiciones de desigualdad. La búsqueda, reafirmación y posesión de prestigio es crucial en la longevidad de un sistema político de la naturaleza del establecido en Chavín de Huántar, el cual al parecer funcionó en un ambiente de intensa competición social.

La competencia puede incrementar el prestigio del centro ceremonial a fin de atraer la mayor cantidad de gente hacia el sistema religioso que lo auspicia. En muchos casos, los recién iniciados contribuirán económicamente con el centro ya sea con fuerza de trabajo y/u ofrendas, los individuos tendrán que decidir a qué centro apoyar, contribuir, alinearse. ¿Por qué estos sistemas sociales estuvieron dispuestos a aliarse o alinearse con un centro ceremonial? La definición de "poder" nos puede ayudar a responder estas preguntas. Poder puede ser entendido como una habilidad para hacer algo o influenciar a alguien, es "la probabilidad de que un actor, al interior de una relación social, esté en la posición de llevar a cabo su voluntad a pesar de cualquier resistencia [traducción del autor]" (Weber 1978:53).

La capacidad de influenciar a diferentes centros ceremoniales fue también responsable del prestigio de Chavín de Huántar. Los centros ceremoniales del período Formativo, probablemente estuvieron 


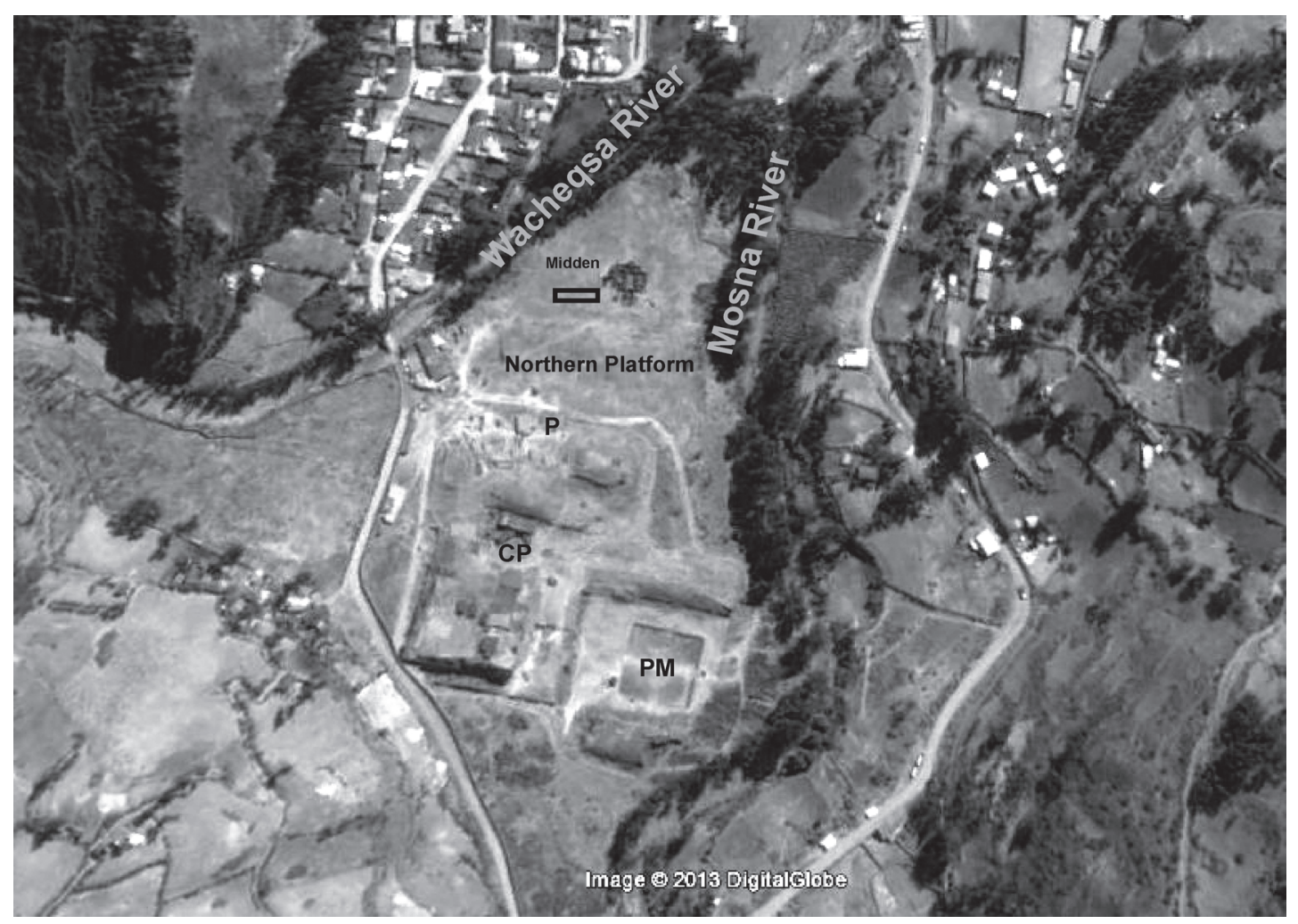

Figura 23. Ubicación de las tres plazas que posiblemente sirvieron como escenarios de festines.

Location of the three plazas that possibly served as feasting sites.

adoctrinando a diversas élites en el sistema religioso Chavín (Kembel y Rick 2004; Rick 2005, 2008); este modelo precisa que las élites arribaron a Chavín con la finalidad de ser iniciadas en un sistema de creencias que les permitiera legitimar su autoridad y legitimar su poder en sus respectivos lugares de origen. Este sistema estuvo apoyado por una "manipulación estratégica de conceptos tradicionales como el shamanismo [traducción del autor]" (Rick 2005:3). No se trata de una cesión de poder, debido a que lo que se transmite no es poder, sino más bien los mecanismos para obtenerlo y ejercerlo.

La autoridad emerge en Chavín como resultado de esta manipulación

la cual habría creado una conciencia colectiva entre los miembros del sistema de creencias [...] La familiaridad con el shamanismo, y el reconocimiento preexistente del contacto humano con las poderosas fuerzas de la naturaleza, es una base creíble que apoya el argumento de que aquellos involucrados en la práctica
Chavín (sacerdotes en el sitio, conversos al culto) podrían poseer poderes derivados de la naturaleza, o tal vez, incluso ser descendientes de poderosos ancestros [traducción del autor] (Rick 2005:80).

El uso de drogas podría haber servido para presentar una realidad alternativa en la cual las conexiones con los poderes derivados de la naturaleza y las relaciones con poderosos ancestros podrían aparecer como reales y legítimas (Mesía 2007; Rick 2005). La autoridad se legitima mediante la manipulación de prácticas ancestrales (shamanismo) y de élites provenientes de diversos rincones de los andes centrales viajaron a Chavín a fin de ser iniciados en este novedoso sistema religioso de legitimización política.

Un elemento importante a considerar es cómo materializar elementos como poder y autoridad en un ambiente competitivo. Seki y Yoneda (1995) así como De Marrais et al. (1996) han argumentado que poder y autoridad pueden ser materializados mediante eventos ceremoniales, objetos simbólicos, monumentos públicos y escritura. En Chavín de 
Huántar, la imponente arquitectura monumental puede ser considerada en sí misma una declaración de autoridad y, como se ha discutido previamente, las plazas sirvieron como lugares en los cuales los asistentes a las ceremonias se reunieron, presenciaron y participaron en los eventos preparados por las autoridades de Chavín. Los festines pueden ser considerados como uno de los eventos auspiciados por las autoridades de Chavín, como parte de una estrategia política. Los festines supracomunales fueron oportunos escenarios de propaganda, ya que implican una organización eficiente además de una generosa disponibilidad de recursos, "intentar impresionar a los comensales significa disponer de los recursos para obtener y preparar alimentos, fabricar vasijas, ítems de prestigio y objetos rituales [traducción del autor]" (Hayden 2001:28). A pesar del costo implícito en la organización de festines, estos tuvieron un valor adaptativo; los valores adaptativos están "relacionados con el comportamiento que genera un beneficio práctico para la supervivencia, reproducción, salud o calidad de vida [traducción del autor]" (Hayden 2001:28). En un contexto de competición regional, cualquier exhibición posible de éxito es una estupenda propaganda que realza los beneficios del sistema de creencias, especialmente cuando se intenta convencer a otros de que sean parte del mismo, y como ya se ha puntualizado, los festines competitivos se llevan a cabo en lugares singulares, como edificios corporativos. El valor adaptativo descrito por Hayden se aplica a la necesidad de generar espacios de prestigio y/o consumo del ritual o rituales, a fin de permitir la reproducción del sistema que los auspicia y por consiguiente la conservación por parte de las élites a cargo del mismo, de sus posiciones privilegiadas.

Diversos aspectos relacionados con los festines funcionan como medios para cuantificar y ordenar, reduciendo la vaguedad de la situación social y política, promoviendo la comparación social. Por ejemplo, dependiendo de la cantidad y calidad de los recursos movilizados en festines comunales y la frecuencia con la que son movilizados, los festines pueden ser medidas cuantitativas de las habilidades de los organizadores como líderes generosos y eficientes. (Potter 2000). Los festines auspiciados pueden servir como ambientes en los cuales el ritual y conocimiento es controlado e incluso manipulado. Las frecuencias de jarras identificadas en el basural del sector Wacheqsa, sugieren que al mismo tiempo que se consumían grandes cantidades de alimentos, se libaban abundantes bebidas, probablemente alcohólicas, ya que este tipo de bebidas es omnipresente en festines supracomunales (Blitz 1993; DeBoer 200; Dietler y Hayden 2001; Hayden 1995; Jennings 2005; Jennings et al. 2005; Potter 2000), siendo la chicha de maíz el candidato más idóneo. Las jarras son recipientes más apropiados para líquidos, ya que presentan cuellos y bordes restrictos, los cuales son útiles para mantener los contenidos al interior de la vasija y están especialmente adaptados para contener brebajes (Rice 1987). Por otra parte, los tubos de hueso encontrados en el basural brindan evidencia del consumo de alucinógenos durante los festines que ocurrieron en Chavín de Huántar.

Los festines en Chavín de Huántar fueron instrumentos utilizados para materializar el poder que ostentaban las autoridades del centro ceremonial. Fueron espacios en los cuales las autoridades se promocionaron, fueron modos en los cuales se controlaba el conocimiento ritual y se indujo a los feligreses asistentes a unirse al sistema de creencias auspiciado por estas autoridades. Fue parte de un sistema de convencimiento que no requirió de violencia física, creado con la finalidad de atraer feligreses y las contribuciones que llegaban con ellos. Los festines son espacios en donde la jerarquía es explícita en el orden en el cual se sirven los alimentos, como en las pachamancas modernas, el orden en el cual una persona recibe sus alimentos es indicador de su rango. Los festines fueron mecanismos eficientes para crear ambientes competitivos que permitieron a las autoridades de Chavín mantener el prestigio del centro ceremonial y por ende el suyo propio.

En tal sentido, propongo que las autoridades de Chavín de Huántar auspiciaron festines con la finalidad de obtener, reafirmar y conservar prestigio y feligreses. Las autoridades brindaron alimentos, bebidas y sustancias psicotrópicas a las diversas elites que viajaron a Chavín con la finalidad de ser iniciadas en el sistema religioso auspiciado por este centro ceremonial, desarrollado por las autoridades de Chavín para servirse del mismo.

Los festines fueron tan solo una de las diversas estrategias utilizadas por las autoridades de Chavín a fin de ejercer su autoridad a un nivel local y regional. E incluso de existir una jerarquía de festines, estos en sí pudieron tener propósitos y objetivos diferentes, de acuerdo con los comensales que participaron en los mismos. 
Estas estrategias involucraron una cuidadosa planificación en la construcción del centro ceremonial (Kembel 2008; Rick 2008), una consciente modificación del medioambiente a fin de dar cabida al centro ceremonial (Contreras 2007) y mecanismos de manipulación visual y sonora (Kolar 2013; Lumbreras et al. 1976) complementados con la apropiación de tradiciones ancestrales a fin de manipularlas y dar una impresión engañosa de continuidad cultural, lo cual les permitió a estas autoridades crear mecanismos para justificarse como herederos de una tradición shamánica (Rick 2006) y mantener de este modo sus privilegiadas posiciones.

\section{Conclusiones}

Durante el Formativo Tardío, una gran cantidad de desechos fueron arrojados en el extremo sur del sector Wacheqsa de Chavín de Huántar, formando un extenso basural, localizado sobre un antiguo canal del Formativo Medio. Grandes vasijas para cocinar, vasijas para servir de tamaño mediano, una gran cantidad de jarras y una alta e inusual densidad de restos de fauna animal sugieren, en su conjunto, la ocurrencia de festines supracomunales. Adicionalmente, existe evidencia indirecta del consumo de sustancias psicotrópicas durante estos eventos, en la forma de pequeños tubos pulidos, encontrados en asociación directa con los materiales anteriormente mencionados, muy probablemente relacionados con el consumo de Anandenanthera y probablemente Trichocereus pachanoi. Del mismo modo se han recuperado evidencias macrobotánicas que sugieren el consumo de quinua o cañiwa (Chenopodium), frejoles y similares (Fabaceae), papas u ocas (Parenchyma) y calabazas, acompañado probablemente de chicha de maíz fermentado.

La cerámica recuperada en el basural es de naturaleza janabarroide (Rick et al. 2009), datada entre 800 y 500 a.C., siendo contemporánea con la fase arquitectónica Blanco y Negro.

El basural del sector Wacheqsa nos brinda evidencias sobre las estrategias de convencimiento desarrolladas por las autoridades de Chavín, destinadas a ganar el apoyo de diversas élites. Los festines fueron materializaciones de poder y prestigio, de la capacidad de acceder y movilizar recursos.

La riqueza es también definida como "aquello por lo cual la gente trabaja [traducción del autor]" (Stanish 2004), en este sentido, diferentes tipos de riqueza para diferentes tipos de personas eran ofrecidas en Chavín. Como fue propuesto por Rick y Kembel (Kembel y Rick 2004; Rick 2005, 2008), las élites de fuera de Chavín de Huántar llegaron al sitio a fin de ser iniciados en el sistema religioso Chavín, y de este modo legitimar sus autoridades en sus lugares de origen, ellos obtuvieron el conocimiento y medios para alcanzar y conservar autoridad, la cual por ende se convirtió en una mercancía. La autoridad se convierte en mercancía al ser el objetivo de transacciones económicas, las cuales fueron negociadas en los festines así como en otros eventos religiosos (con marcadas connotaciones políticas y económicas) que se llevaron a cabo en Chavín de Huántar. La eficiente administración de esta estrategia fue crucial para el éxito de las autoridades de Chavín y el sistema que representaron.

Agradecimientos: Las investigaciones desarrolladas por el autor en Chavín de Huántar contaron con el financiamiento de la Facultad de Humanidades y Ciencias Sociales de la Universidad de Stanford, del Departamento de Ciencias Antropológicas de la Universidad de Stanford, del Centro de Estudios Latinoamericanos de la Universidad de Stanford y del Centro de Arqueología de la Universidad de Stanford. También contó con el apoyo económico de Global Heritage Fund y de la National Geographic Society. A John Rick por contribuir al desarrollo de la presente investigación y por su camaradería reflejada a lo largo de los años. Igualmente a mis colegas John Wolf, Daniel Contreras, Matt Sayre, Rosa Mendoza, Iván Falconí y Adriana Aguayo. A los editores de Chungara Revista de Antropología Chilena y a tres anónimos revisores quienes realizaron valiosos comentarios al presente trabajo. Desde luego los errores incluidos en el presente trabajo son de exclusiva responsabilidad mía. 


\section{Referencias Citadas}

Aldenderfer, M. 2012. Gimme that old time religion: Rethinking the role of religion in the emergence of social inequality. En Pathways to Power: New Perspectives on the Emergence of Social Inequality, edited by D. Price y G. Feinman, pp. 77-94. Springer, New York.

Bennett, W. 1944. The North Highlands of Peru, Excavations in the Callejon de Huaylas and Chavin de Huantar. Anthropological Papers of the American Museum of Natural History 39. The American Museum of Natural History, New York.

Blitz, J.H. 1993. Big pots for big shots: Feasting and storage in a Mississippian community. American Antiquity 58:80-96.

Boone, J.L., III 1987. Defining and measuring midden catchment. American Antiquity 52:336-345.

Bray, T. 2003. To dine splendidly: Imperial pottery, commensal politics, and the Inca State. En The Archaeology and Politics of Food and Feasting in Early States and Empires: 93-142, editado por T. Bray. Plenum Publishers, New York.

Bronk Ramsey, C. y S. Lee 2013. Recent and planned developments of the program OxCal. Radiocarbon 55:720-730.

Burger, R. 1982. Pojoc and Waman Wain: Two Early Horizon villages in the Chavin Heartland. Nawpa Pacha 20:3-40.

- - - 1984. The Prehistoric Occupation at Chavín de Huántar, Perú. University of California Publications, Anthropology 14. University of Berkeley, Berkeley.

- - - - 1988. Unity and Heterogeneity within the Chavin Horizon. En Peruvian Prehistory: An Overview of Pre-Inca and Inca Society, edited by R. Keatinge, pp. 99-144. Cambridge University Press, Cambridge.

- - - 1992. Chavin and the Origins of Andean Civilization. Thames and Hudson, London.

- - - 1998. Excavaciones en Chavín de Huántar. Pontificia Universidad Católica del Perú, Lima.

- - - 2000. Los Orígenes de la Civilización en los Andes. En Historia de la Cultura Peruana. Congreso de la República del Perú, Lima.

- - - 2011. What kind of Hallucinogenic snuff was used at Chavín de Huántar? Nawpa Pacha 31:123-140.

Burger, R.L. y R. Matos Mendieta 2002. Atalla: A center on the periphery of the Chavin Horizon. Latin American Antiquity 13:153-177.

Burger, R. y L. Salazar-Burger 1991. The second season of investigations at the initial period center of Cardal, Peru. Journal of Field Archaeology 18:275-296.

Burger, R. y N. Van Der Merwe 1990. Maize and the origin of highland Chavín Civilization: An isotopic perspective. American Anthropologist, New Series 92:85-95.

Clark, J. y M. Blake 1996. The power of prestige: Competitive generosity and the emergence of rank societies in Mesoamerica. En Contemporary Theory in Archaeology: A Reader, editado por R. Preucel e I. Hodder, pp. 258-281. Blackwell Publishing, Oxford.
Contreras, D. 2007. Geomorphologic and Sociopolitical Change at Chavín de Huantar. Ph.D Dissertation, Department of Anthropological Sciences, Stanford University, Stanford.

- - - 2009. Reconstructing landscape at Chavin de Huantar, Peru: A GIS-based approach. Journal of Archaeological Science 36:1006-1017.

Cook, A. 2004. Wari art and society. En Andean Archaeology, edited by H. Silverman, pp. 146-166. Blackwell Publishing, Oxford.

Cook, A. y M. Glowacki 2003. Pots, politics, and power: Huari ceramic assemblages and imperial administration. En The Archaeology and Politics of Food and Feasting in Early States and Empires: 173-202, editado por T. Bray. Kluwer Academic, New York.

Chicoine, D. 2011. Feasting landscapes and political economy at the Early Horizon center of Huambacho Nepeña valley, Peru. Journal of Anthropological Archaeology 30:432-453.

DeBoer, W. 2001. The big drink: Feast and forum in the Upper Amazon. En Feasts, Archaeological and Ethnographic Perspectives on Food, Politics and Power, editado por M. Dietler y B. Hayden, pp. 215-239. Smithsonian Institution Press, Washington DC.

DeMarrais, E., L.J. Castillo y T. Earle 1996. Ideology, materialization, and power strategies. Current Anthropology 37:15-31.

Dietler, M. 1995. Feasts, commensal politics in the political economy: Food, power, and status in prehistoric Europe. En Food and the Status Quest, edited by P. Wiessner y W. Schiefenhovel, pp. 87-126. Berghahn Books, Oxford.

Dietler, M. y B. Hayden 2001. Digesting the feast-good to eat, good to drink, good to think: An introduction. En Feasts, Archaeological and Ethnographic Perspectives on Food, Politics and Power, editado por M. Dietler y B. Hayden, pp. 1-22. Smithsonian Institution Press, Washington DC.

Dietler, M. e I. Herbich 2001. Feasts and labor mobilization: Dissecting a fundamental economic practice. En Feasts, Archaeological and Ethnographic Perspectives on Food, Politics and Power, editado por M. Dietler y B. Hayden, pp. 240-266. Smithsonian Institution Press, Washington DC.

Diess1, W. 2004. Huantar, San Marcos, Chavín. Sitios Arqueológicos en la Sierra de Ancash. Instituto Cultural Runa, Lima.

Durkheim, É. 1947. The Elementary Forms of the Religious Life: A Study in Religious Sociology. Free Press, New York.

Espejo, J. 1956. Exploraciones Arqueológicas en las Cabeceras del Pukcha. Tesis para optar el grado de bachiller en Humanidades. Universidad Nacional Mayor de San Marcos, Lima.

Hayden, B. 1995. Pathways to power, principles for creating socioeconomic inequalities. En Foundations of Social Inequality, editado por D. Price y G. Feinman, pp. 15-85. Plenum Press, New York.

- - - 2001 Fabulous feasts: A Prolegomenon to the importance of feasting. En Feasts, Archaeological and Ethnographic Perspectives on Food, Politics and Power, editado por M. Dietler y B. Hayden, pp. 23-64. Smithsonian Institution Press, Washington DC. 
Ikehara, H. y K. Shibata 2005. Festines e integración social en el período Formativo: nuevas evidencias de Cerro Blanco, valle bajo de Nepeña. Boletín de Arqueología PUCP 9:123-159.

Ikehara, H., F. Paipay y K. Shibata 2013. Feasting with Zea Mays in the Middle and Late Formative North Coast of Peru. En Latin American Antiquity 24:217-231.

Jennings, J. 2005. La Chichera y el Patron: Chicha and the energetics of feasting in the Prehistoric Andes. En Foundations of Power in the Prehispanic Andes, editado por V. Kevin, D. Ogburn y C. Conlee, vol. 14, pp. 241-259. American Anthropological Association, San Diego.

Jennings, J., K.L. Antrobus, S.J. Atencio, E. Glavich, R. Johnson, G. Loffler y Ch. Luu 2005. "Drinking beer in a blissful mood": alcohol production, operational chains, and feasting in the Ancient World. Current Anthropology 46:275-303.

Kauffman-Doing, F. y M. González 1993. 24 Planos Arquitectónicos de Chavín de Huántar. Museo Nacional de Arqueología, Antropología e Historia del Perú, Instituto de Investigaciones Antropológicas, Lima.

Kaulicke, P. 2010. Las Cronologías del Formativo: 50 Años de Investigaciones Japonesas en Perspectiva. Fondo Editorial de la Pontificia Universidad Católica del Perú, Lima.

Kembel, S. 2001. Architectural Sequence and Chronology at Chavin de Huantar, Peru. Ph.D Dissertation. Department of Anthropological Sciences. Stanford University, Stanford.

- - - 2008. The Architecture at the Monumental Center of Chavín de Huántar: Sequence, Transformation and Chronology. Proceedings of the Chavin: Art, Architecture and Culture, pp. 35-84.

Kembel, S. y J. Rick 2004. Building Authority at Chavín de Huántar: Models of Social Development in the Initial Period and Early Horizon. En Andean Archaeology, editado por H. Silverman, pp. 51-76. Blackwell Publishing, Oxford.

Kolar, M. 2013. New evidence for ritual sound environment: use and design at Chavín de Huántar, Peru. Paper presented at the Society for American Archaeology 78th Annual Meeting. Honolulu, Hawaii.

Lau, G.F. 2002. Feasting and ancestor veneration at Chinchawas, north highlands of Ancash, Peru. Latin American Antiquity 13:279-304.

Lumbreras, L. 1977. Excavaciones en el Templo Antiguo de Chavín (Sector R). Informe de la Sexta Campaña. Ñawpa Pacha 15:1-38.

- - - 1989. Chavín de Huántar en el Nacimiento de la Civilización Andina. Instituto de Estudios Andinos, Lima.

- - - 1993. Chavín de Huántar, Excavaciones en la Galería de las Ofrendas. KAVA, Mainz.

- - 2005. Arqueología y Sociedad. Instituto de Estudios Peruanos, Lima.

- - - 2007. Chavín: Excavaciones Arqueológicas I. Universidad Alas Peruanas, Lima.

Lumbreras, L. y H. Amat 1965. Informe preliminar sobre las galerías interiores de Chavín. Revista del Museo Nacional 34:143-197.
Lumbreras, L., Ch. González y B. Lietaer 1976. Acerca de la Función del Sistema Hidráulico de Chavín. Serie Investigaciones de Campo 2. Editado por R. Shady. Museo Nacional de Arqueología y Antropología.

Matsumuto, Y. 2010. The Prehistoric Ceremonial Center of Campanayuq Rumi: Interregional Interactions in the Peruvian South-Central Highlands. PhD dissertation, Yale University.

- . - 2012. Recognising ritual: the case of Campanayuq Rumi. Antiquity 86:746-759.

Mercer, R. 1985. A Neolithic fortress and funeral center. Scientific American 252:94-101.

Mesia, Ch. 2007. Intrasite Spatial Organization at Chavín de Huántar during the Andean Formative: Three Dimensional Modeling, Stratigraphy and Ceramics. Ph.D Dissertation. Department of Anthropological Sciences. Stanford University, Stanford.

- - - 2012. Uso de Estimados de Densidad Kernel en la investigación de grupos cerámicos del período Formativo provenientes de Chavín de Huántar. Arqueología y Sociedad 24:161-190.

Miller, G.R. y R.L. Burger 1995. Our father the cayman, our dinner the llama: Animal utilization at Chavin de Huantar, Peru. American Antiquity 60:421-458.

- - - 2000. Ch'arki at Chavin: Ethnographic models and archaeological data. American Antiquity 65:573-576.

Mills, B. 1999. Ceramics and Social Contexts of Food Consumption. En Pottery and People, A Dynamic Interaction, editado por J. Skibo y G. Feinman, pp. 99-114. Foundations of Archaeological Inquiry. University of Utah Press, Utah.

Murra, J. 1960. Rite and Crop in the Inca State. En Culture in History: Essays in Honor of Paul Renin, editado por S. Diamond, pp. 393-407. Columbia University Press, New York.

Onuki, Y. 1995. Kuntur Wasi y Cerro Blanco, Dos Sitios del Formativo en el Norte del Perú. Hokusen-Sha, Tokyo.

Phillips, D. y L. Sebastian 2004. Large-scale feasting and politics: an essay on power in precontact southwestern societies. En Identity, Feasting and the Archaeology of the Greater Southwest, editado por B. Mills, pp. 233-260. The University Press of Colorado, Boulder.

Potter, J.M. 2000. Pots, parties, and politics: Communal feasting in the American Southwest. American Antiquity 65:471-492.

Reimer, P.J., M.G.L. Baillie, E. Bard, A. Bayliss, J. Warren Beck, P.G. Blackwell, C. Bronk Ramsey, C.E. Buck, G.S. Burr, R.L. Edwards, M. Friedrich, P.M. Grootes, T.P. Guilderson, I. Hajdas, T.J. Heaton, A.G. Hogg, K.A. Hughen, K.F. Kaiser, B. Kromer, F.G. McCormac, S.W. Manning, R.W. Reimer, D.A. Richards, J.R. Southon, S. Talamo, C.S.M. Turney, J. van der Plicht y C.E. Weyhenmeyer 2009. IntCa109 and Marine09 Radiocarbon Age Calibration Curves, 0-50,000 Years Cal BP. Radiocarbon 5:1111-1150.

Renfrew, C. y P. Cherry 1986. Introduction. Peer polity interaction and sociopolitical change. En Peer Polity Interaction and Sociopolitical Change, editado por C. Renfrew y P. Cherry, pp. 1-18. Cambridge University Press, Cambridge.

Rice, P. 1987. Pottery Analysis, a Sourcebook. The University of Chicago Press, Chicago. 
Rick, J. 2005. The Evolution of Authority and Power at Chavin de Huantar, Peru. En Foundations of Power in the Prehispanic Andes, editado por K.J. Vaughn, D.E. Ogburn y Ch.A. Conlee, pp. 71-89. vol. 14. American Anthropological Association, Los Angeles.

- - - 2006. Chavín de Huántar: Evidence for an evolved shamanism. En Mesas and Cosmologies in the Central Andes, editado por D. Sharon, vol. 44,pp. 101-112. San Diego Museum, San Diego.

- - - 2008. Context, construction, and ritual in the development of authority at Chavín de Huantar. En Chavín: Art, Architecture and Culture, editado por W. Conklin y J. Quilter, pp. 3-34. Cotsen Institute of Archaeology, Los Angeles.

Rick, J., Ch. Mesía, D. Contreras, S. Kembel, M. Sayre y J. Wolf 2009. La cronología de Chavín de Huántar y sus implicancias para el Período Formativo. Boletín de Arqueología PUCP 13:89-132.

Rick, J., S. Kembel, R. Mendoza y J. Kembel 1998. La arquitectura del Complejo Ceremonial de Chavín de Huántar: documentación tridimensional y sus implicancias. Boletín de Arqueología PUCP 2:181-214.

Rivero, M. 2012 [1851]. Antigüedades Peruanas. Editorial Maxtor, Valladolid.

Rosenswig, R.M. 2007. Beyond identifying elites: Feasting as a means to understand early Middle Formative society on the Pacific Coast of Mexico. Journal of Anthropological Archaeology 26:1-27.

Rowe, J. 1962. Chavin Art, an Inquiry into its Form and Meaning. The Museum of Primitive Art, New York.

Sayre, M. 2010. Life across the river: Agricultural, ritual, and production practices at Chavin de Huantar, Peru. Ph.D
Dissertation. Department of Anthropology. California State University at Berkeley.

Seki, Y. y M. Yoneda 2005. Cambios de manejo del poder en el Formativo: desde el análisis de la dieta alimenticia. Perspectivas Latinoamericanas, Nanzan University, The Center for Latin American Studies 2:110-131.

Stanish, Ch. 2004. The evolution of chiefdoms, an economic anthropological model. En Archaeological Perspectives on Political Economies, editado por G. Feinman y L.Nicholas, pp. 7-24. The University of Utah Press, Salt Lake City.

Tello, J.C. 1940. Expedición a Chavín (del 7 de Noviembre al 14 de Diciembre de 1940), pp. 101. vol. Bulto 53, Cuadernillo 5. Universidad Nacional Mayor de San Marcos. Archivo Tello, Lima.

_ _ _ 1960. Chavín Cultura Matriz de la Civilización Andina. Universidad Nacional Mayor de San Marcos, Lima.

Torres, C. 2008. Chavin's psychoactive pharmacopeia: The iconographic evidence. En Chavin: Art, Architecture and Culture, editado por W. Conklin y J. Quilter, pp. 237-260. Cotsen Institute of Archaeology, Dumbarton Oaks.

Torres, C. y D. Repke 2006. Anadenanthera: Visionary Plant of Ancient South America. Haworth Herbal Press, New York.

Vega-Centeno, R. 2007. Construction, labor organization, and feasting during the Late Archaic Period in the Central Andes. Journal of Anthropological Archaeology 26:150-171.

Weber, M. 1978. Economy and Society I. University of California Press, Los Angeles.

Whalen, M. y P. Minnis 2004. Casas Grandes and its Hinterland: Prehistoric Regional Interaction in Northwest Mexico. University of Arizona Press, Tucson.

\section{Notas}

1 La cronología utilizada en el presente trabajo es la planteada por Kaulicke, 2010.

2 Quien se refiere a la existencia de otro edificio monumental en las cumbres de Pojoq (ubicado a más de $4.000 \mathrm{msm}$, frente al centro ceremonial de Chavín), el cual fue excavado casi siglo y medio después por Burger (Burger 1982).

3 Los términos urrabarroide y janabarroide están explicados en Rick et al. 2009.
4 No existe correlación directa entre el volumen de líquidos que una jarra puede contener y el diámetro de su boca. Una correlación directa se ha encontrado entre el tamaño de la jarra y el volumen (Mills 1999), pero lamentablemente los fragmentos de jarras analizados no son lo suficientemente grandes como para proveer información de la altura de las mismas.

5 Los vasos tan solo representan el 1,5\% de la muestra analizada. 
